\title{
Fire Experiment Inside a Very Large and Open-Plan Compartment: $x$-ONE
}

\author{
Egle Rackauskaite, Matthew Bonner, Francesco Restuccia, Nieves Fernandez \\ Anez, Eirik G. Christensen and Nils Roenner, Imperial College London, \\ London, UK \\ Wojciech Wegrzynski and Piotr Turkowski, ITB, Warsaw, Poland \\ Piotr Tofilo, The Main School of Fire Service, Warsaw, Poland \\ Mohammad Heidari, CERIB, Épernon, France \\ Panagiotis Kotsovinos, Arup Fire, Manchester, UK \\ Izabella Vermesi, Franz Richter, Yuqi Hu, Chloe Jeanneret, Rahul Wadhwani \\ and Guillermo Rein (D), Imperial College London, London, UK
}

Received: 28 July 2020/Accepted: 20 July 2021/Published online: 30 September 2021

\begin{abstract}
The traditional design fires commonly considered in structural fire engineering, like the standard fire and Eurocode parametric fires, were developed several decades ago based on experimental compartments smaller than $100 \mathrm{~m}^{2}$ in floor area. These experiments led to the inherent assumption of flashover in design fires and that the temperatures and burning conditions are uniform in the whole of the compartment, regardless of its size. However, modern office buildings often have much larger open-plan floor areas (e.g. the Shard in London has a floor area of $1600 \mathrm{~m}^{2}$ ) where non-uniform fire conditions are likely to occur. This paper presents observations from a large-scale fire experiment $x-O N E$ conducted inside a concrete farm building in Poland. The objective of $x-O N E$ was to capture experimentally a natural fire inside a large and open plan compartment. With an open-plan floor area of $380 \mathrm{~m}^{2}, x-O N E$ is the largest compartment fire experiment carried out to date. The fire was ignited at one end of the compartment and allowed to spread across a continuous wood crib (fuel load $\sim 370 \mathrm{MJ} / \mathrm{m}^{2}$ ). A travelling fire with clear leading and trailing edges was observed spreading along $29 \mathrm{~m}$ of the compartment length. The flame spread rate was not constant but accelerated with time from $3 \mathrm{~mm} / \mathrm{s}$ to $167 \mathrm{~mm} / \mathrm{s}$ resulting in a gradually changing fire size. The fire travelled across the compartment and burned out at the far end $25 \mathrm{~min}$ after ignition. Flashover was not observed. The thermocouples and cameras installed along the fire path show clear near-field and far-field regions, indicating highly non-uniform spatial temperatures and burning within the compartment. The fire dynamics observed during this experiment are completely different to the fire dynamics reported in small scale compartments in previous literature and to the assumptions made in traditional design fires for structural design. This highlights the need for further research and experiments in large compartments to understand the fire dynamics and continue improving the safe design of modern buildings.
\end{abstract}

\footnotetext{
*Correspondence should be addressed to: Guillermo Rein, E-mail: g.rein@imperial.ac.uk
} 
Keywords: Flame spread, Travelling, Compartment, Flashover, Design fire

\section{Introduction}

The traditional compartment design fires most commonly assumed in structural fire design, like the standard fire [1] and Eurocode parametric fires [2], were based on the observations of fire dynamics from experimental compartments smaller than $100 \mathrm{~m}^{2}$ in floor area [3]. These experiments led to the inherent assumption of flashover in traditional design fires and that the temperatures and burning conditions are relatively uniform in the whole of a compartment regardless of its size. Eurocode EN 1991-1-2 [2] permits the use of the parametric fire curves in compartments with floor areas of up to $500 \mathrm{~m}^{2}$. However, this limit is based on the collective experience of the standards committees and are not supported by experimental evidence because there is a lack of fire experiments in large compartments. Nonetheless, traditional design fires may be representative for a large fraction of buildings with typically smaller compartments such as residential buildings, hotels, or small offices. However, modern architectural preferences for large and open compartments often end up exceeding these limits [2]. For example, a survey of buildings in the campus of the University of Edinburgh [4] has shown that $16 \%$ of the total volume of newly constructed buildings are over the $500 \mathrm{~m}^{2}$ floor area limitation within the Eurocode. For open-plan offices and public uses, recent proposals by architects include large open-plan floor areas that are up to $5000 \mathrm{~m}^{2}$, far greater than the compartments for which experimental data is available. Therefore, architectural trends force fire safety engineers to design outside known limitations (see Fig. 1) which poses questions on the applicability of traditional methods for modern compartments.

The standard fire and the Eurocode parametric curves assume uniform burning and homogeneous temperature distributions in the compartment. However, even in small scale experiments temperatures have been observed to vary significantly in space. Bøhm and Hadvig [5] carried out 17 full-scale compartment fire experiments (floor area of $\sim 21 \mathrm{~m}^{2}$ ) and found spatial horizontal and vertical differences in gas temperatures of $200-500^{\circ} \mathrm{C}$ (approximately $10-20 \%$ from the compartment average). Variation in temperature in excess of $200^{\circ} \mathrm{C}$ has also been observed during Natural Fire Safety Concept (NFSC) tests at Cardington in a compartment of 144 $\mathrm{m}^{2}$ [6], and during the Dalmarnock test $\left(\sim 17 \mathrm{~m}^{2}\right)$ [7]. Stern-Gottfried et al. [8] carried out a review of data from various experiments and found large variations of temperature up to $230^{\circ} \mathrm{C}$ (up to $-38 \%$ and $+49 \%$ from the compartment average). Although there is a lack of data from experiments in large compartments due to the costs and complexities of such experiments, it is expected that temperature variations in large compartments would be even more significant.

Moreover, in some large fire accidents, flames have been observed to burn over a limited area and travel across floor plates and between stories. These fires are referred to as travelling fires [9] and have been observed during the Interstate Bank fire in Los Angeles, USA (1988); One Meridian Plaza fire in Philadelphia, USA (1991); WTC 1, 2, and 7 fires in New York, USA (2001); Windsor Tower 


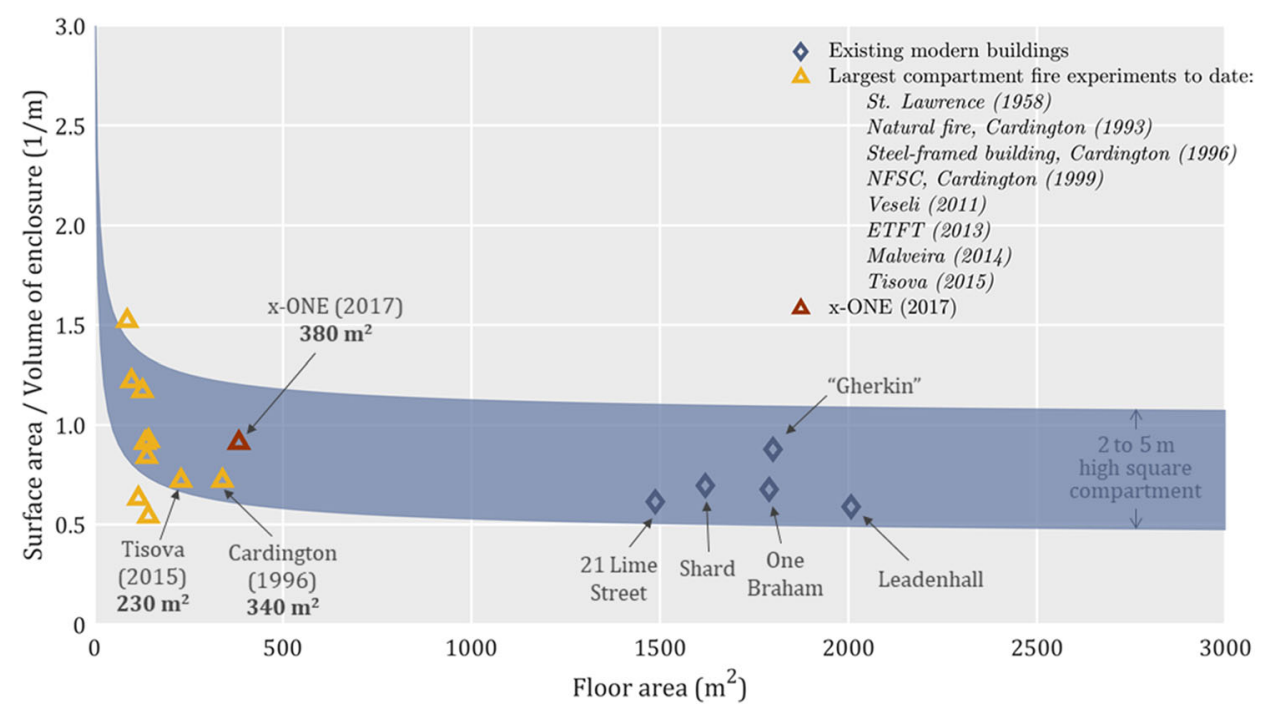

\begin{abstract}
Figure 1. Comparison of the surface area to volume ratio of compartments within which experiments have been carried out to date, and recently constructed tall buildings in London, UK. The shaded area represents a range of typical surface area to volume of enclosure ratios for a rectangular square compartment with floor to ceiling heights between $2 \mathrm{~m}$ and $5 \mathrm{~m}$.
\end{abstract}

fire in Madrid, Spain (2005); Faculty of Architecture building fire at TU Delft, Netherlands (2008); and Plasco building fire in Tehran, Iran (2017). In all of these accidents, the fires lasted for up to $7 \mathrm{~h}$ or even $20 \mathrm{~h}$ for the Windsor Tower and Meridian Plaza fires. Such long fire durations are not considered and cannot be reproduced in current codes and standards for structural fire design. Prolonged periods of fire can result in structural elements reaching higher temperatures in longer fires in comparison to shorter fires [10] as structural materials have more time to heat up. Heating of structural materials has an effect on thermal expansion, deformations, and loss of material strength, and thus the load-carrying capacity of the structure.

In previous research [11, 12], design methodologies accounting for travelling fires of different sizes have been shown to lead to more severe thermal conditions for a structure than a uniform whole floor fire. For example, the peak rebar temperature in the study by Stern-Gottfried and Rein [12] was calculated to be $556^{\circ} \mathrm{C}$ under travelling fires, while for the same fuel load density considering Eurocode parametric fire curves, rebar reached a peak temperature of $363^{\circ} \mathrm{C}$.

In terms of the structural response, modelling studies [11, 13-16] indicate that certain travelling fires can also be more severe than uniform fires. Travelling fires for some structures have been found to result in larger residual displacements [13, 16]; larger residual tensile forces and bending moments [11, 15]; more onerous 
strains and stresses within the concrete frame [11]; and irregular displacement and oscillating stress development patterns that are not experienced in the case of uniform fires [13-16]. In these studies [11, 13-16], it was concluded that consideration of travelling fires is important for the structural response, as such fires may result in higher stresses, strain, and structural response mechanisms not observed for uniform fires, and that a uniform fire assumption is not always the most conservative.

Movement of fires around an enclosure has been observed in a limited number of experiments as reviewed in [9, 17]. Kirby et al. [18] conducted nine natural fire tests in a $23 \mathrm{~m}$ long $\times 6 \mathrm{~m}$ wide (floor area of $138 \mathrm{~m}^{2}$ ) and $3 \mathrm{~m}$ high compartment at Cardington with uniformly distributed wood cribs $\left(1 \mathrm{~m}^{2}\right.$ each) and ventilation provided at one end only. Fire loading and ventilation effects on behaviour of natural fires were studied. Fuel was ignited in one crib line at the rear of the enclosure. The fire was observed to spread towards the front of the enclosure (i.e. the ventilation opening), then, after the fuel at the front burnt out, progressed back and ceased at the rear. Flashover in these experiments was not observed [18].

More recently, four large scale experiments aimed at studying fire dynamics in large compartments have been conducted and reported in the literature to date [19-24]. Horova et al. [19, 20] conducted a fire experiment in a structure with a floor area of $\sim 140 \mathrm{~m}^{2}$ (4 m high) in Veselí nad Lužnicí, Czech Republic in 2011. A continuous wood crib was used as the fuel $\left(\sim 173.5 \mathrm{MJ} / \mathrm{m}^{2}\right)$ and ignited at one end. The results indicated a fast spreading travelling fire with temperature differences of up to $400^{\circ} \mathrm{C}$ in the upper smoke layer.

In 2013, a series of experiments were conducted at the BRE in UK and are referred to as ETFT [21, 22]. Twelve experiments were conducted in total using either gas burners or wood cribs as fuel in the compartment with an area of $90 \mathrm{~m}^{2}$ (2 m high). Flame development (gas burners) and ventilation characteristics were varied. Results indicated non-uniform spatial temperature distributions along the length and height of the compartment [25].

Following the ETFT experiments, a full-scale fire experiment was carried out in an industrial building with a floor area of $\sim 100 \mathrm{~m}^{2}$ in Malveira, Portugal in 2014 [23]. A continuous wood crib was used as fuel $\left(\sim 420 \mathrm{MJ} / \mathrm{m}^{2}\right)$, which was ignited at one end. During the experiment, the flames were observed to spread at a constant rate until the fire reached an area with a layer of cork attached to the ceiling and began to rapidly grow in size when the ceiling ignited. Non-uniform spatial temperature distributions within the compartment were recorded.

Lastly, Rush et al. [24] carried out an experiment inside of a concrete framed building with a floor area of $\sim 230 \mathrm{~m}^{2}$ in Tisova, Czech Republic in 2015. A continuous wood crib was used $\left(\sim 680 \mathrm{MJ} / \mathrm{m}^{2}\right)$ and ignited at one end. The observed fire spread during the experiment was very slow due to a very high moisture content of wood $(18-22 \%)$. For most of the fire duration, temperatures within the 


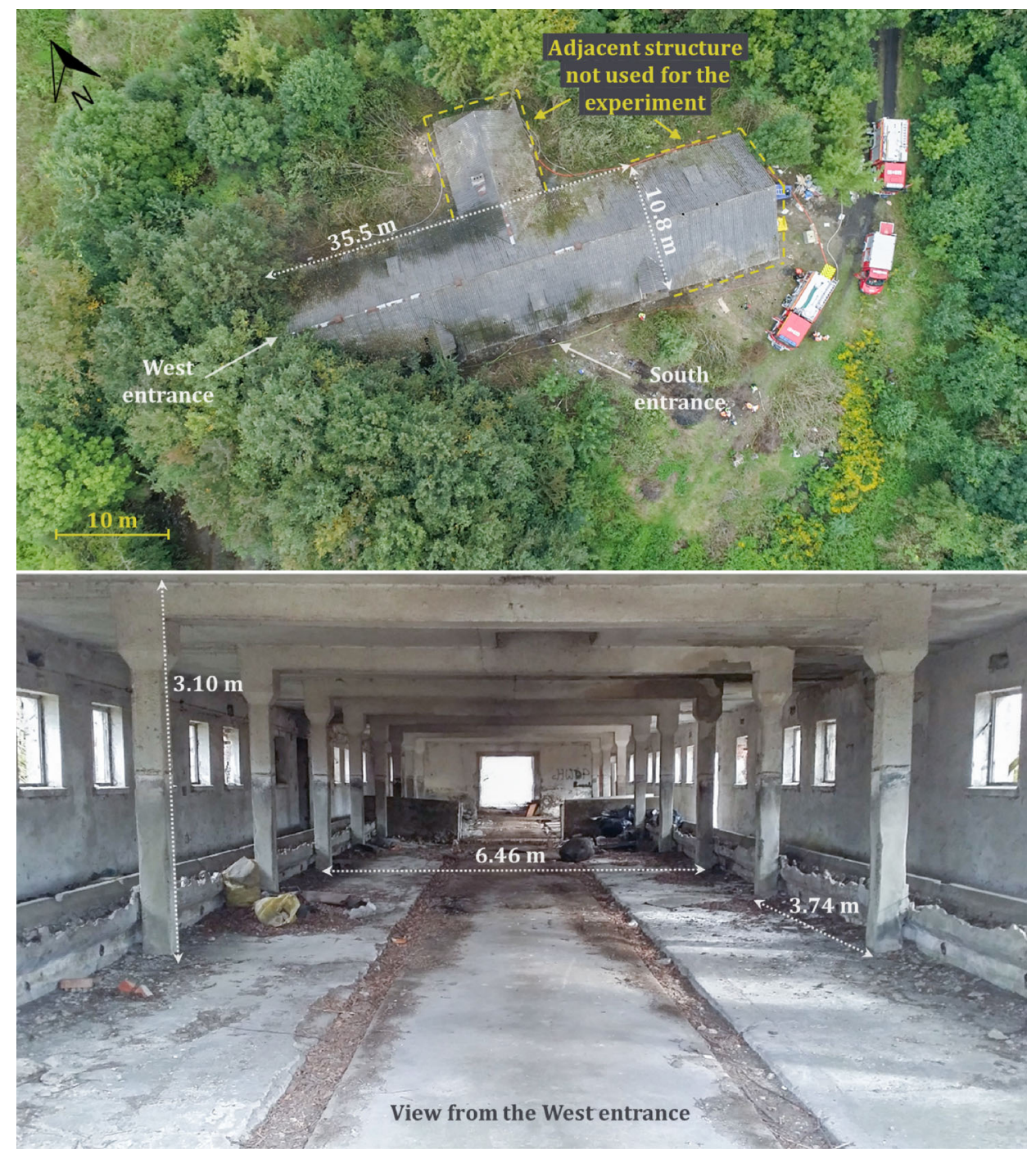

\section{Figure 2. Plan view photograph of the building (top) and internal view of the compartment (bottom) of "Obora' where the x-ONE experiment was carried out taken before the set-up of the experiment.}

compartment stayed below $500^{\circ} \mathrm{C}$ with significant variation of temperatures reported through the height of the compartment.

The largest fire experiment to date was conducted as part of the Cardington tests in a multi-storey steel framed building [26] in 1996. One of these experiments (i.e. Test 5) had a floor area of $340 \mathrm{~m}^{2}$ but all of the wood cribs used as fuel were ignited simultaneously and therefore the spread of fire was not observed. Very limited information was reported on the fire dynamics and thermal conditions in 


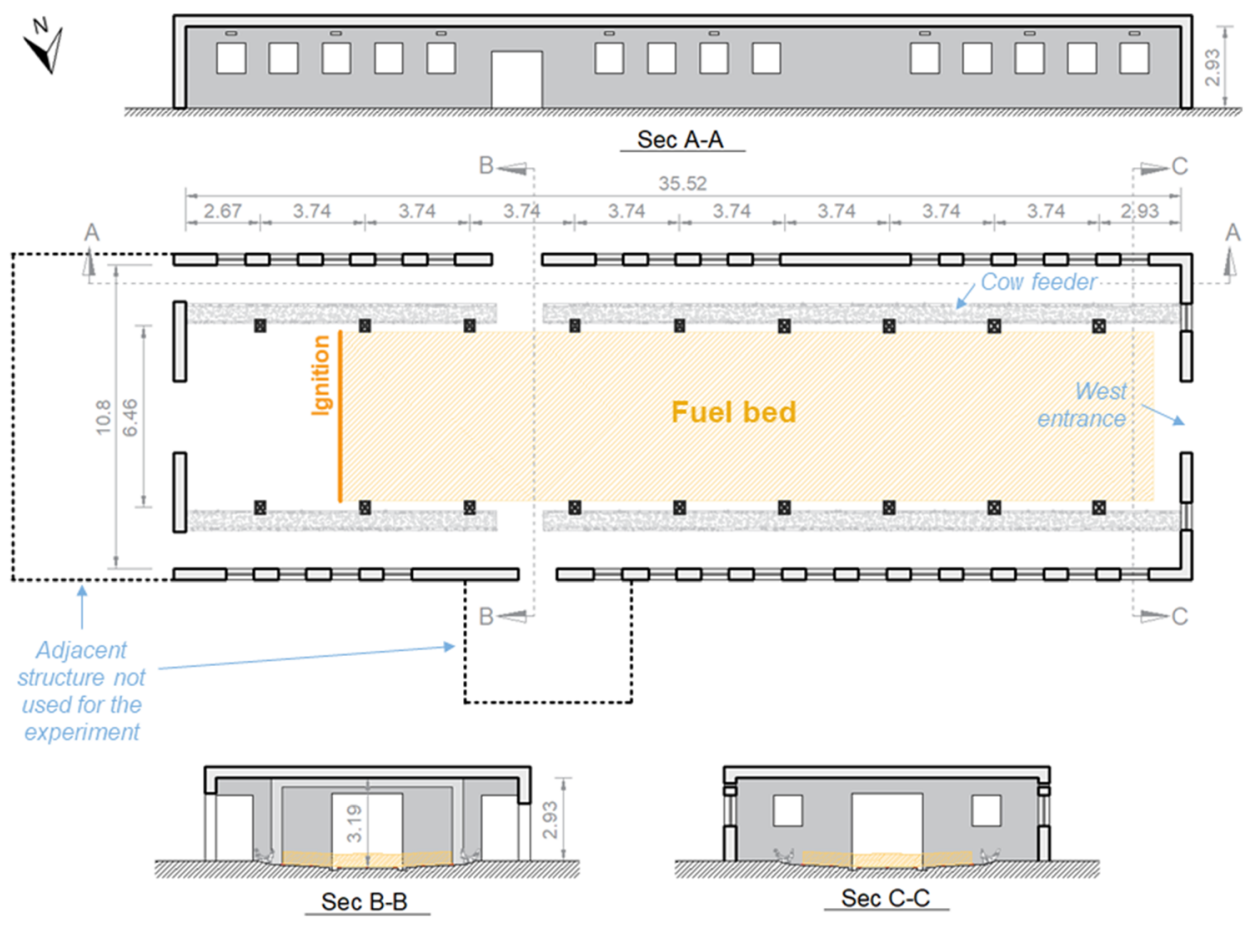

\section{Figure 3. Floor plan and sections of the 'Obora' compartment used for the x-ONE experiment. Units in meters.}

the compartment as the experiment instead focused on the structural response. It is unknown if the fire travelled or not.

Compartments with larger floor areas have smaller surface area to volume ratios which depart from the conditions in the small experiments conducted to date and assumed in uniform design fires. Modern structures such as, for example, the Shard and 21 Lime street in London have open plan floor areas in excess of $1500 \mathrm{~m}^{2}$, more than 4 times higher than the largest compartment fire experiment conducted to date (see Fig. 1). Compartment geometry characteristics of a number of modern structures in London are compared to the largest compartments where fire experiments have been conducted to date in Fig. 1. A range of surface area to volume ratios are illustrated for a rectangular square compartment with floor to ceiling heights between $2 \mathrm{~m}$ and $5 \mathrm{~m}$. An important knowledge gap can be clearly seen, indicating a need for fire experiments in large enclosures in order to develop and improve design fire methodologies that could be used for the design of modern open-plan structures. This is in the interest of both safety and sustainability. It is important to understand whether extrapolation of experimental data to larger enclosures is conservative or not.

Therefore, to observe experimentally a fire inside a large compartment, $x$ $O N E$ was carried out in Poland in September 2017. The experiment has been named $x-O N E$ as it is the first of a series of experiments within the same com- 


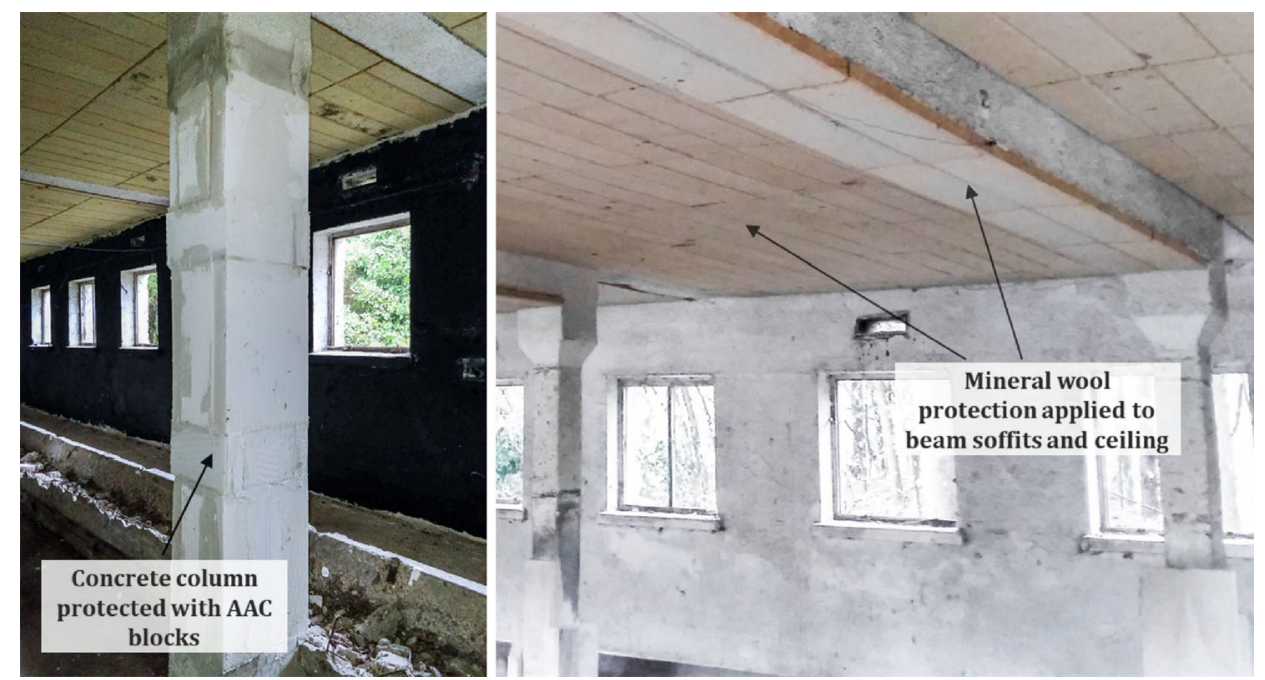

\section{Figure 4. Final protection of the structure with autoclaved aerated concrete (AAC) blocks for the concrete columns (left), and mineral wool for the ceiling and beam soffits (right).}

partment. It is the largest fire experiment in terms of compartment floor area (i.e. $380 \mathrm{~m}^{2}$ ) carried out to date. Most of the compartment fire experiments have been carried out in significantly smaller enclosures as indicated previously and in Fig. 1. The results of this experiment could then be used to build upon and design future experiments which consider other fuel loads, ventilation, and internal lining effects.

\section{2. x-ONE Experiment}

\subsection{The 'Obora' Building}

The building where the $\mathrm{x}$-ONE experiment was carried out is located in a rural area, Golaszew, within Warsaw West County in Poland. It is approximately $20 \mathrm{~km}$ west of Warsaw. It was originally constructed as a concrete farm building (a cow farmhouse) and we refer to it by its name in Polish, 'Obora'. Photos of the building from the top and inside prior to the set-up of the experiment can be seen in Fig. 2. The building has one floor that is mostly open plan, and an attic. It has thick, external masonry walls. The beam and block concrete slab ceiling is supported by 18 reinforced concrete columns, beams, and external masonry walls. The compartment has 10 bays. The structure supporting the roof is made from timber.

The experiment was carried out in the open plan section of the building which has a floor area of $380 \mathrm{~m}^{2}$, though, air ventilated and smoke was allowed to move via the adjacent compartment at the East entrance. The floor of the tested 


\section{Table 1}

Opening dimensions along different elevations of the building used for the $x$-ONE experiment

Building elevation

East (Sec B-B in Fig. 3)

South (Sec A-A in Fig. 3)

West (Sec C-C in Fig. 3)

North
Door openings

(number $\times$ width $\times$ height)

Window openings

(number $\times$ width $\times$ height)

$\begin{array}{lll}1 \times 2.54 \mathrm{~m} \times 2.66 \mathrm{~m} & \text { None } \\ 2 \times 1.31 \mathrm{~m} \times 2.34 \mathrm{~m} & \\ 1 \times 1.80 \mathrm{~m} \times 20.3 \mathrm{~m} & 14 \times 1.00 \mathrm{~m} \times 1.09 \mathrm{~m} \\ 1 \times 2.54 \mathrm{~m} \times 2.66 \mathrm{~m} & 2 \times 1.00 \mathrm{~m} \times 1.09 \mathrm{~m} \\ 1 \times 1.37 \mathrm{~m} \times 2.38 \mathrm{~m} \text { (closed) } & 15 \times 1.00 \mathrm{~m} \times 1.09 \mathrm{~m} \text { (1 closed) }\end{array}$
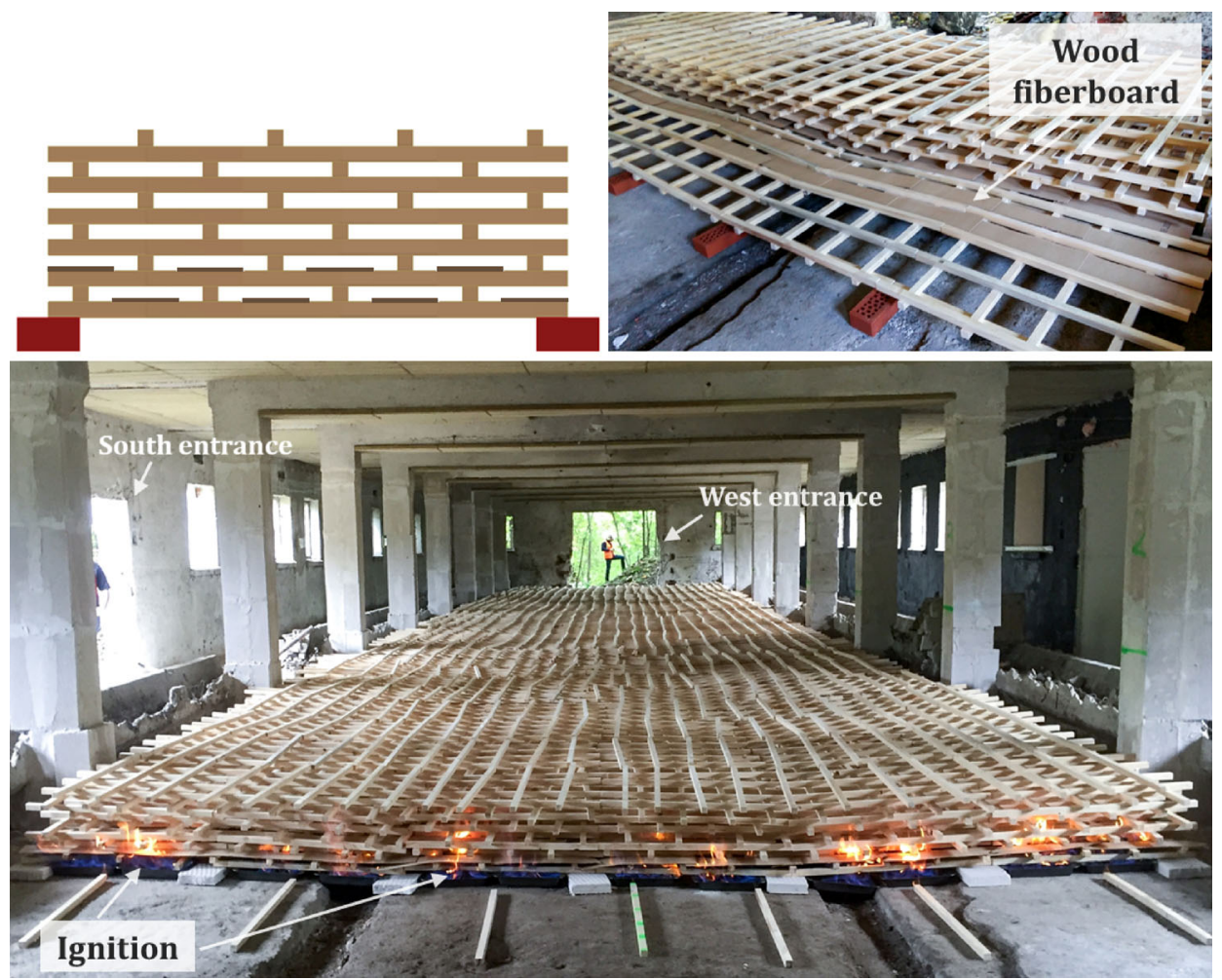

Figure 5. Illustration and photos of the final wood crib and fibreboard arrangement used as fuel for the $x$-ONE experiment. Wood stick dimensions were $3 \mathrm{~cm} \times 3 \mathrm{~cm} \times 1 \mathrm{~m}$. The bottom image shows completed wood crib at the moment of ignition. 
compartment is $10.8 \mathrm{~m}$ wide, $35.5 \mathrm{~m}$ long and $3.19 \mathrm{~m}$ high. A sketch of the floor plan and sections of the building are shown in Fig. 3.

In order to obtain the precise dimensions and layout of the compartment, a three-dimensional (3D) laser scan was conducted prior to the experiment. Laser scanning is a technique that captures the shapes of spaces in which the laser scanner is placed by measuring the distances and angles between the points and the instrument. These points create a $3 \mathrm{D}$ point cloud that can be used to visualize and gather information from the space with an error of up to $\pm 10 \mathrm{~mm}$.

\subsection{Protection of the Structure}

Upon initial inspections of the building, many concrete columns supporting the ceiling were found to be damaged with missing concrete cover and exposed steel rebar which, if exposed to fire, could lead to collapse. Therefore, the structure was protected. All the columns were protected with autoclaved aerated concrete (AAC) blocks with the dimensions of $48 \mathrm{~cm} \times 24 \mathrm{~cm} \times 12 \mathrm{~cm}$. The ceiling slab and beam soffits were protected with $5 \mathrm{~cm}$ thick mineral wool $\left(80 \mathrm{~kg} / \mathrm{cm}^{3}\right)$. Some of the applied protection is shown in Fig. 4. All the openings to the attic were closed to prevent the entry of smoke or flames to the attic in order to protect the timber structure supporting the roof.

\subsection{Ventilation}

There are 6 door and 31 window openings in the building. Opening dimensions are given in Table 1. All openings were left open in order to reduce the effects of walls on the fire dynamics and to represent an open-plan compartment.

Only the door and the window openings to the adjacent structure along the North elevation of the building were closed to keep the fire compartment simple and with openings directly to outside only.

In total, $20 \%$ of the compartment wall surface area, $A_{w}=56 \mathrm{~m}^{2}$, constituted openings with an opening factor of $0.0694 \mathrm{~m}^{1 / 2}\left(A_{w} \sqrt{h} / A_{\text {total }}\right.$, where $A_{\text {total }}$ is the total surface area) and a weighted average opening height, $h$, of $1.67 \mathrm{~m}$ as defined in Annex A of Eurocode 1 [2]. Opening factors are commonly used to quantify the relative amount of ventilation in a fire compartment.

\subsection{Fuel Load}

The fuel load was an arrangement of a continuous wood crib mixed with fibreboard (see Fig. 5). The final wood crib arrangement was based on a preliminary study on the burning of wood cribs (see Rackauskaite and Rein [27] for more detail). In total, the final fire load was approximately $370 \mathrm{MJ} / \mathrm{m}^{2}\left(19.4 \mathrm{~kg} / \mathrm{m}^{2}\right)$ and covered a floor area of $174 \mathrm{~m}^{2}(6 \mathrm{~m} \times 29 \mathrm{~m})$ as illustrated in Fig. 3. The fuel bed was placed $1 \mathrm{~m}$ from the West entrance. This fuel load was chosen to limit the risk of damage to the structure but to still be within the range of typical fuel load densities in office buildings (250-950 MJ/m² [28]; average $420 \mathrm{MJ} / \mathrm{m}^{2}$ [29]).

In some previous large scale fire experiments carried out by Hidalgo et al. [23], and Rush et al. [24], a relatively slow flame spread has been observed in the range 

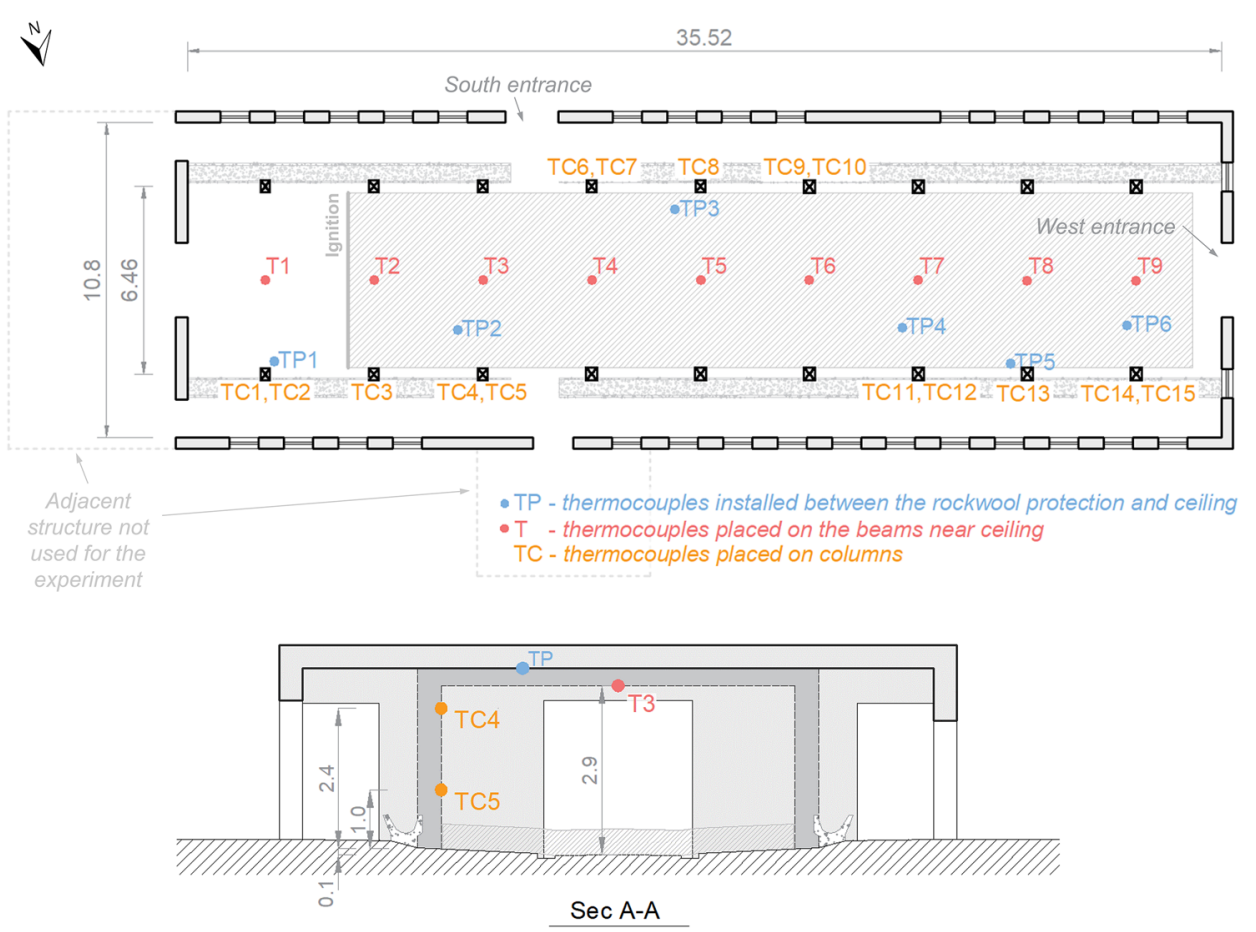

Figure 6. Indicative location of thermocouples within the compartment. Plan view (top), and Section view (bottom). TP-thermocouples installed between the mineral wool protection and the ceiling; T-thermocouples placed at the mid-span of beam soffits at the height of $\sim 2.9 \mathrm{~m}$; TC-thermocouples placed on the columns. Where there are two thermocouples at the same column, they are located at the heights of $1 \mathrm{~m}$ and $2.4 \mathrm{~m}$ from floor level while a single thermocouple is located at the height of $2.4 \mathrm{~m}$ from the floor level. All dimensions are given in meters.

of $\sim 13$ to $54 \mathrm{~mm} / \mathrm{min}$ for the first $237 \mathrm{~min}$ until acceleration along the remaining fuel [23], and at an estimated average of $55 \mathrm{~mm} / \mathrm{min}$ for $7 \mathrm{~h} \mathrm{[24].} \mathrm{These} \mathrm{spread}$ rates are lower than could be expected in real large compartment fires where large amounts of combustible materials such as paper, plastic, and furniture are present [30]. In real accidental fires, flames have been observed to spread in the range of $150-1000 \mathrm{~mm} / \mathrm{min}(2.5-16.7 \mathrm{~mm} / \mathrm{s})$ [31]. Therefore, to aim for faster flame spreads than in previous experiments, it was decided to introduce additional material within the wood crib. Wood fibreboard (4 mm thick with a density of $250 \mathrm{~kg} / \mathrm{m}^{3}$ ) was selected for the experiment based on a set of small-scale exploratory experiments.

For the wood crib, softwood sticks with the dimensions of $3 \mathrm{~cm} \times 3 \mathrm{~cm} \times 100$ $\mathrm{cm}$, density of $426-466 \mathrm{~kg} / \mathrm{m}^{3}$ (average $453 \mathrm{~kg} / \mathrm{m}^{3}$ ), heat of combustion of $18.94 \pm 0.14 \mathrm{MJ} / \mathrm{kg}$, and moisture content of $9.3 \pm 0.3 \%$ (on dry basis) were 
used. Wood fibreboard had a heat of combustion of $19.60 \pm 0.18 \mathrm{MJ} / \mathrm{kg}$. A sample of 50 wood sticks was collected on the day of the experiment and weighted to obtain a representative average wood density. A sub-sample of 15 wood sticks were then dried in the oven at $80^{\circ} \mathrm{C}$ to obtain their moisture content. Bomb calorimetry was used to measure the heat of combustion. These wood and fibreboard properties have been used to determine the fire load.

The wood crib was arranged to have 11 stick layers with 4 sticks $/ \mathrm{m}$ in each layer with an additional 2 sticks $/ \mathrm{m}$ as the bottom layer (i.e. 12 stick layers in total), and 2 layers of $4 \mathrm{~mm}$ thick wood fibreboard (cut into strips of $0.59 \mathrm{~m} \times 0.79 \mathrm{~m}$ and placed between wood sticks) as illustrated in Fig. 5. This is based on the study reported in [27]. The wood crib was lifted from the ground by placing bricks every $1 \mathrm{~m}$ to reduce heat losses to the concrete floor and enable air supply and burning below the crib.

The fuel was ignited by placing a line of 12 pans $(15 \mathrm{~cm} \times 25 \mathrm{~cm})$ filled with 0.51 methanol each at one end of the wood crib (i.e. East Entrance). The objective was to ignite them simultaneously to ensure a uniform line of ignition. Fire across the wood crib was allowed to spread naturally. Illustration of the fuel load at ignition is shown in Fig. 5.

\subsection{Instrumentation}

2.5.1. Thermal In total, 30 Type-K thermocouples (see Fig. 6) were uniformly distributed across the compartment to measure temperatures. The number of the thermocouples was carefully selected to be enough to capture the key fire dynamics phenomena of interest, i.e. spatial temperature distributions at the ceiling level along the expected fire path, and vertical temperature distributions at a few selected locations.

15 Type-K thermocouples were attached to 9 columns (TC) and 9 to the soffits of beams (T) at the mid-span. Thermocouples were attached to 9 columns in total. On all selected columns, thermocouples were attached at the height of $2.4 \mathrm{~m}$ with 6 columns having an additional thermocouple at the height of $1 \mathrm{~m}$ to capture vertical temperature variations. Columns of interest were selected on each side of the compartment. Beam thermocouples were attached to the soffits of the beams at mid-span at the height of approximately $2.9 \mathrm{~m}$. The thermocouples were evenly spaced to capture spatial temperature distributions at the ceiling level along the length of the compartment. In addition, 6 thermocouples (TP) were installed above the blocks of mineral wool, in contact with the original ceiling, to measure the surface temperature of the ceiling and monitor the fire protection.

The thermocouple measurements were corrected for radiation errors using a simple methodology referred to in this paper as the $\beta$-method. It is assumed that each thermocouple is in thermal equilibrium (quasi steady-state), equating the convective and radiative components as follows:

$$
h\left(T_{g}-T_{T C}\right)-\dot{q}_{r f}^{\prime \prime}+\varepsilon \sigma T_{T C}^{4}=0
$$


where $h$ is the convection coefficient, $T_{g}$ is the gas temperature around the thermocouple, $T_{T C}$ is the recorded temperature at the thermocouple, $\dot{q}_{r f}^{\prime \prime}$ is the radiative incident heat flux on the thermocouple, $\varepsilon$ is the thermocouple surface emissivity (0.9 [32]), and $\sigma$ is the Stefan-Boltzmann constant.

The radiative heat flux received to the thermocouple due to the fire, $\dot{q}_{r f}^{\prime \prime}$, is unknown but can be assumed to be proportional to $T_{T C}^{4}$. Hence, $\dot{q}_{r f}^{\prime \prime}=\beta \varepsilon \sigma T_{T C}^{4}$, where $\beta$ is a dimensionless constant (defined as the correction coefficient) greater than 1, as the radiative heat flux due to the fire will always result in $T_{T C}$ greater than $T_{g}$. Thus, $T_{g}$ can be calculated as follows:

$$
T_{g}=T_{T C}+\frac{\varepsilon \sigma}{h}(1-\beta) \cdot T_{T C}^{4}
$$

$h$, is determined by evaluating the Nusselt number for flow around a sphere as described by Welch et al. [33] assuming a local velocity of $u=12 \mathrm{~m} / \mathrm{s}$. Due to variation in gas density with temperature, $h$ is varies throughout the experiment.

The thermocouple corrections are based on parametric analysis varying $\beta$. As shown in fire experiments reported by Drysdale [34], the maximum average flame temperature measured by corrected thermocouples in turbulent flames is $900^{\circ} \mathrm{C}$. Therefore, by setting $900^{\circ} \mathrm{C}$ as the maximum value of $T_{T C}$, we can find a range of values for $\beta$ through Eq. (2). The values of $\beta$ were calibrated to correct the peak thermocouple temperatures measured in the follow up experiment $\mathrm{x}$-TWO. 1 $\left(1100^{\circ} \mathrm{C}\right)[35]$ to produce a local gas temperature within the range of $900-1000^{\circ} \mathrm{C}$. A corrected temperature range was, thus, selected for the $\beta$ values $1.17 \leq \beta \leq 1.25$, which also captures the error associated with thermocouple measurements.

2.5.2. Visual A series of visual cameras were used to capture the flame size and spread rate. Nine raspberry-pi cameras were attached to the internal wall near the South entrance of the compartment to capture the fire development. They were pre-programmed to take time-lapse photos every $10 \mathrm{~s}$ and send them to the computer on-site via a wi-fi connection. The cameras were protected with plasterboard and fixed to a wall. However, only one of the raspberry-pi cameras survived despite the protection. One GoPro was located outside the building close to the West entrance to record video footage and track flame spread from the East end of the compartment where the fire was ignited. Additional footage included photos and videos recorded with 7 handheld and mobile cameras.

All of this footage was used in the image processing analysis described in "Appendix 1" to measure the locations of the leading (i.e. flame front) and trailing (i.e. burn-out) edges of the fire. In the analysis, the tomographic reconstruction approach by Graham [37] was adapted in MATLAB. The steps in the image processing analysis included calibrating each camera to correct for image distortion; detecting the location of each camera with respect to the 'Obora' building; and flame detection in images, all of which were then used to determine the location of flames in the building. An algorithm was developed to determine geometric relationship between building voxels and projected flame pixel rays. The error associ- 
South entrance

view across compt.
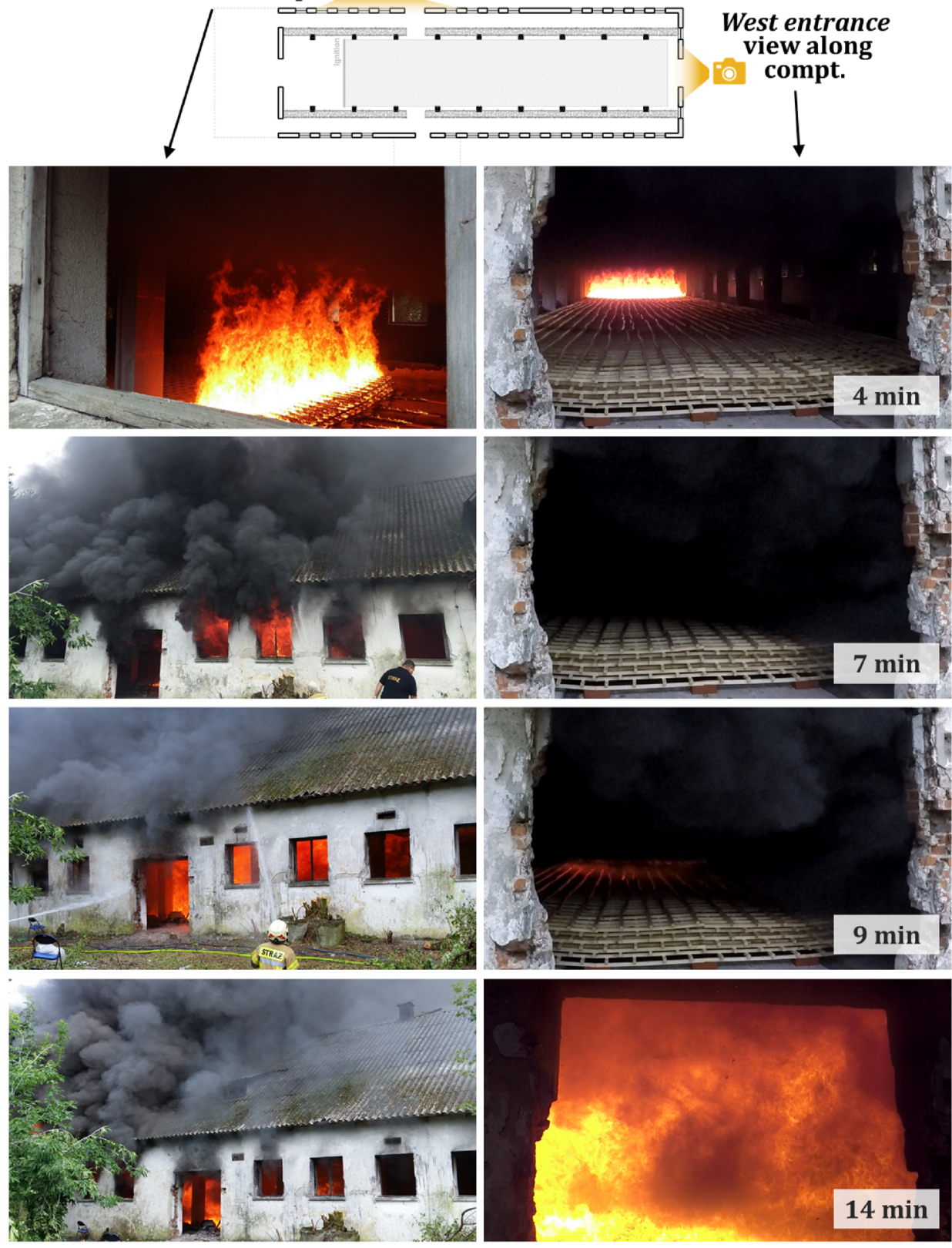

Figure 7. Photos taken from two different locations at four different times during the experiment showing fire development and progress. Left and right columns show view across the compartment taken outside of the South and West entrances, respectively. 

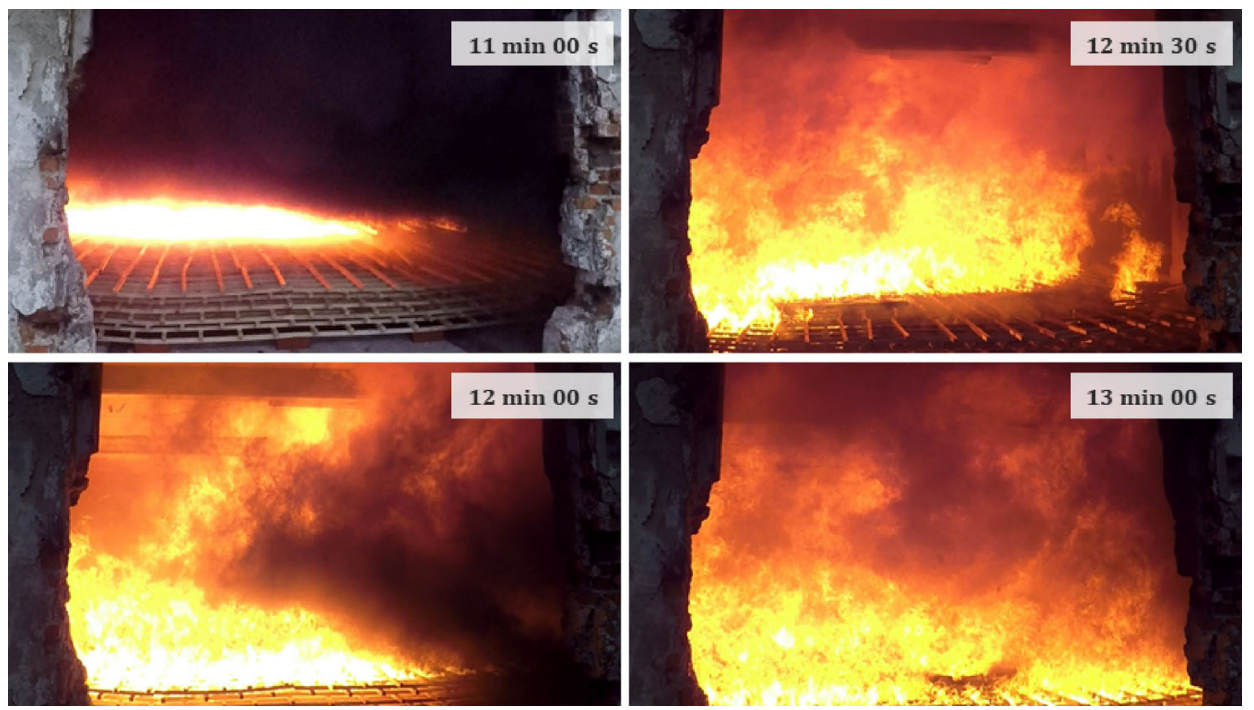

Figure 8. Location of the flame front between $11 \mathrm{~min}$ and $13 \mathrm{~min}$ of the experiment. Photos taken outside of South entrance.

ated with image processing and flame detection is estimated to be $\pm 0.25 \mathrm{~m}$ and \pm $0.5 \mathrm{~m}$ for the leading and trailing edges, respectively (see "Appendix 1").

2.5.3. 3D Scan A 3D laser scan prior to the experiment was conducted to obtain the dimensions of the compartment. After the experiment, a further 3D laser scan was conducted to capture any deformations that may have taken place in the compartment due to fire. The deflections after the fire experiment have been quantified by comparing the measurements from the two sets of scans.

2.5.4. Weather A weather station was placed outside of the building by the East entrance at approximately 1 to $1.5 \mathrm{~m}$ above ground to track weather conditions. The weather station recordings measured the outside wind during the experiment to be, predominantly, from Southwest-West with wind speeds in the range of $0.3-$ $2.0( \pm 1.0) \mathrm{m} / \mathrm{s}$ (light breeze). Air temperature and relative humidity were measured to be in the range of $17.6-19.4( \pm 1.0)^{\circ} \mathrm{C}$ and $75-80 \%( \pm 5 \%)$, respectively, throughout the duration of the experiment.

\section{Experiment Results}

\subsection{Observations}

After ignition, a line fire formed along the width of the wood crib and started to spread along the length of the compartment. Figure 7 illustrates fire photos taken 


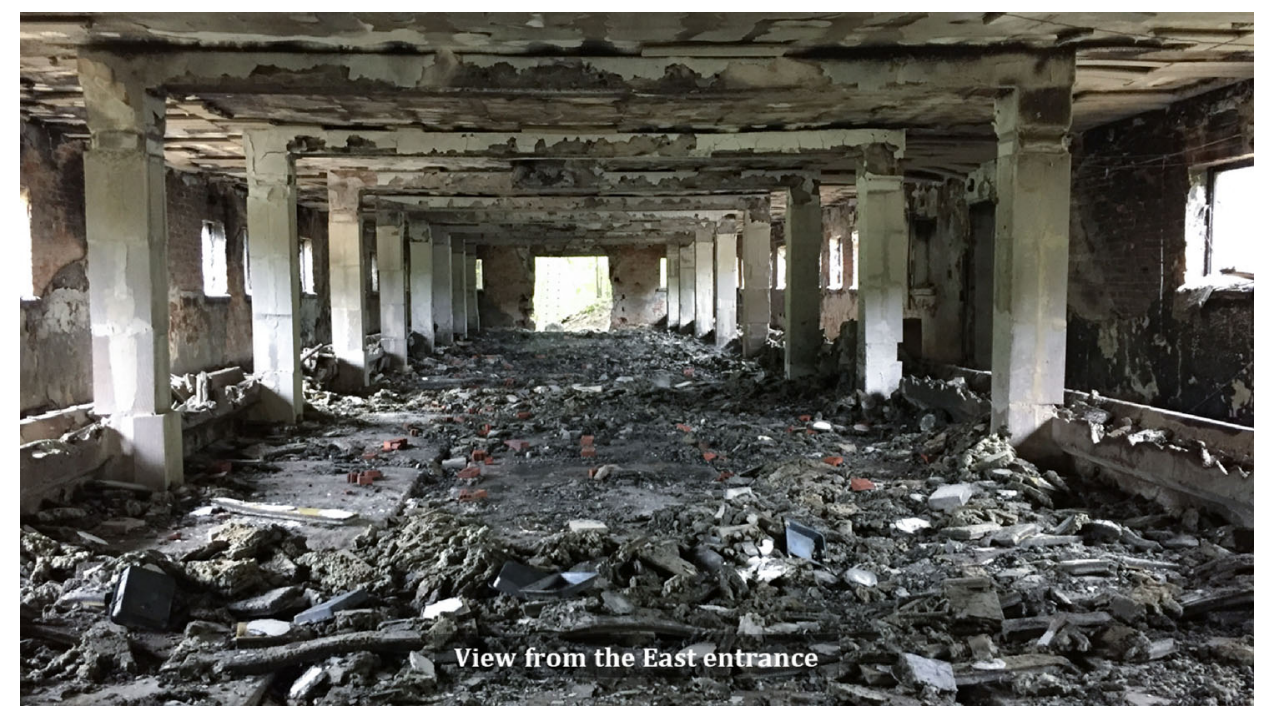

Figure 9. Illustration of the compartment after the experiment showing mineral wool protection which has fallen down from the ceiling and beams as fire progressed through the compartment.

from two different locations (i.e. South entrance and West entrance) at four different times during the experiment.

Initially, the fire spread relatively slowly (i.e. $\sim 1 \pm 0.25 \mathrm{~m}$ in $5.5 \mathrm{~min}, 3 \mathrm{~mm} / \mathrm{s}$ ). Flames impinged on the ceiling at approximately $5.5 \mathrm{~min}$ after ignition and at this time the flame spread rate increased continuously until the fire reached the South entrance (see Fig. 3) at $\sim 10$ min. After the fire spread past the South entrance, the flames accelerated towards the West end of the compartment. The fire reached the far end of the compartment (i.e. West entrance) at approximately $12 \mathrm{~min}$ (see Fig. 8) and burned out completely approximately $25 \mathrm{~min}$ after ignition. Measurements of the leading and trailing edges and flame spread rates are reported in Sect. 3.2.

A smoke layer started to form in the compartment from the moment of ignition and grew in extension and depth (see Fig. 7). At $7 \mathrm{~min}$, the flames were no longer visible from the West entrance due to a build-up of the smoke layer. Smoke was mainly exhausted via the windows adjacent to the location of the flames (where localised internal and external flaming was observed) and the South and West entrances with air coming in through the remaining windows and below the neutral plane of the South and West entrances. 
Figure 10. Indicative visualisations of leading and trailing edge, fuel bed, fire, and burnt out areas in the compartment (top left) and expected variation with respect to time and location in the compartment (top right); Location of leading and trailing edges measured during the experiment (middle); and corresponding spread rates of the leading edge and trailing edge, i.e. burn out, with respect to time (bottom). Extracted locations of the flames are indicated as crosses " $x$ " and asterisks "*' for the leading edge and trailing edge, respectively. Continuous lines represent best fit curves. Where insufficient visual data was available to measure the locations of the trailing edge, data was interpolated and is represented by a dashed line.

Towards the end of the compartment and while a thick smoke layer was still present at approximately $11 \mathrm{~min}$, the fire spread over the fuel bed. As the small crib surface flames reached the West entrance at $\sim 12 \mathrm{~min}$, they were pushed back by fresh air from the West entrance. The flames spread back towards the entrance again at approximately $13 \mathrm{~min}$. The location of the flame front between $11 \mathrm{~min}$ and 13 min is shown in Fig. 8.

External flaming was only observed locally from a limited number of windows at any time during the fire, as can be seen in Fig. 7. This is representative of a fuel-controlled fire rather than a ventilation-controlled fire where external flaming would be observed from all openings. No sudden fire growth or flashover was observed. There was limited involvement from the fire service who only protected the exterior of the building to prevent the spread of fire and damage to the roof.

An image of the compartment after the experiment can be seen in Fig. 9 showing complete burn out of the fuel all over the compartment as well as mineral wool, which had fallen. The mineral wool applied as protection to the ceiling and beam soffits fell off after the fire exposure due to the failure of mortar (used to fix it to the ceiling) and $2 \mathrm{~mm}$ plastering which covered the original ceiling. It is unlikely to have had a significant effect on the fire development as it only happened after the flames had impacted the area. Fire protection to the columns remained in place and no structural damage was observed to either the columns or the ceiling.

In order to quantify and understand the observed fire behaviour better, visual image processing (see "Appendix 1") and gas phase temperature measurements are reported and discussed in the following sections (Sect. 3.2 and Sect. 3.4, respectively).

\subsection{Leading and trailing edges}

A travelling fire burns over a limited area and spreads across the compartment. Two characteristics defining travelling fires are the leading and trailing edges [9]. The leading edge is the front of a spreading flame, while the trailing edge is the location where fuel burn out and cessation of visible flaming takes place, as illustrated in Fig. 10. 

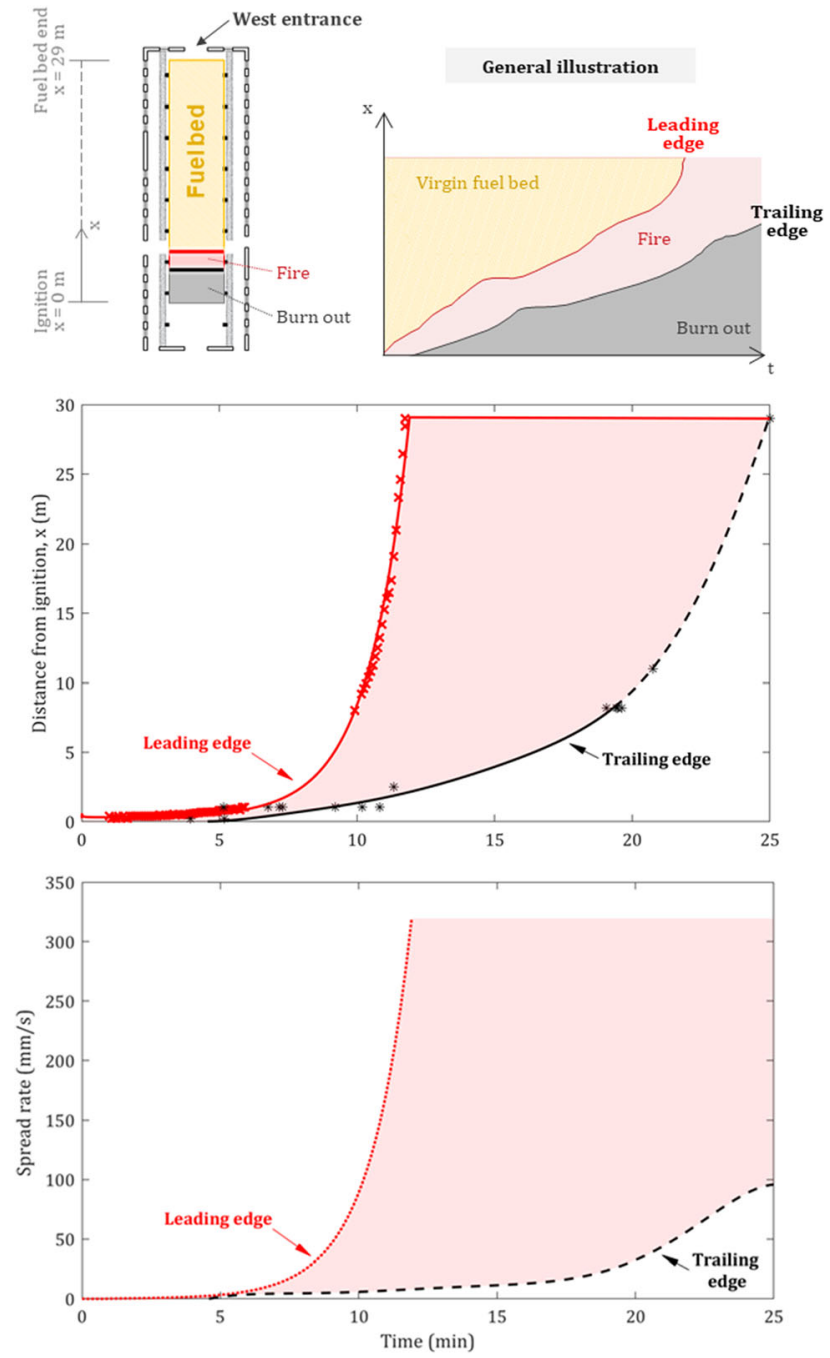
Location and spread rates of the leading and trailing edges with time are extracted from the visual evidence and observations taken during the experiment and illustrated in Fig. 10. Lines for the leading and trailing edges represent best fit curves for each set of data. Where insufficient visual data was available to measure the locations, best fit was extrapolated and is represented by a dashed curve.

The flame spread rate was not constant but gradually accelerating, as can be seen in Fig. 10. Two distinct phases when the fire accelerated, and the spread rate increased are observed: $\sim 5.5 \mathrm{~min}$ after ignition when the flames started to impinge on the ceiling and $\sim 10 \mathrm{~min}$ when the fire spread approximately $1.3 \pm 0.25 \mathrm{~m}$ past the South entrance. In the initial phase, flame spread rate was approximately $3 \mathrm{~mm} / \mathrm{s}$, which then increased to $\sim 21 \mathrm{~mm} / \mathrm{s}$ and $\sim 167 \mathrm{~mm} / \mathrm{s}$ at $5.5 \mathrm{~min}$ and at $\sim 10 \mathrm{~min}$, respectively.

A clear trailing edge was observed at 5 min onwards. The rate of the burn out edge was not constant during the experiment but increased with time although less than the spread rate of the leading edge. Between $5 \mathrm{~min}$ and $20 \mathrm{~min}$, the rate of the trailing edge was $\sim 12 \mathrm{~mm} / \mathrm{s}$, which then increased to $\sim 65 \mathrm{~mm} / \mathrm{s}$. Therefore, different spread rates of the leading and trailing edges had resulted in a continuously growing fire size during the experiment.

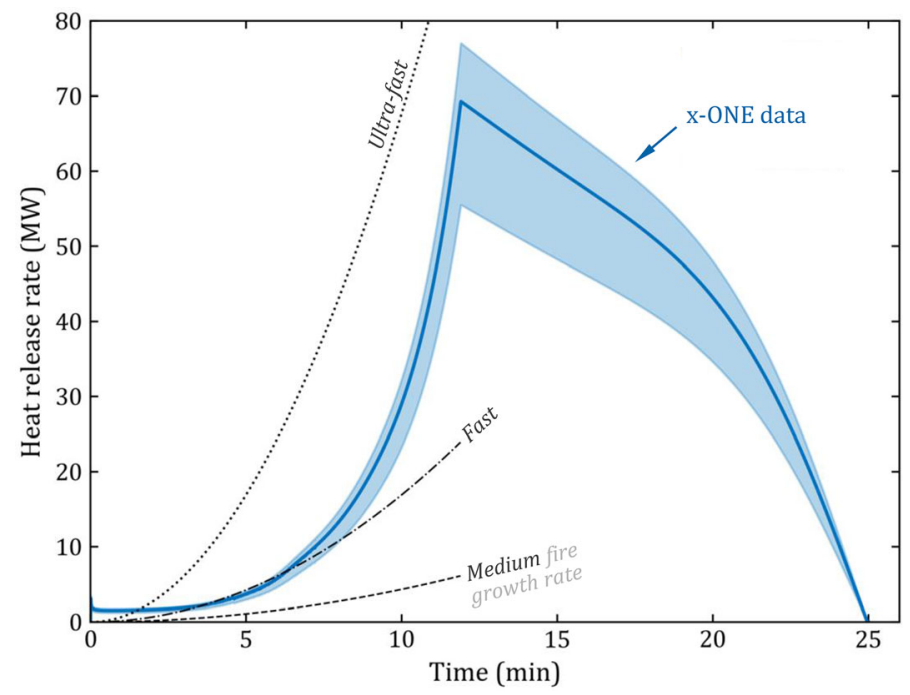

Figure 11. The heat release rate (HRR) evolution that is estimated based on the locations of leading and trailing edges of the fire and different fire growth rates for comparison. The shaded area represents uncertainty associated with assumed combustion efficiency (0.6-0.75), wood density (426-466 kg/ $\left.\mathrm{m}^{3}\right)$, and heat of combustion (18.94 $\pm 0.14 \mathrm{MJ} / \mathrm{kg})$. 


\subsection{Heat Release Rate}

Based on the size of the fuel bed of $174 \mathrm{~m}^{2}$, fire load of $\sim 370 \mathrm{MJ} / \mathrm{m}^{2}$, the total fire duration of $\sim 25 \mathrm{~min}$, and 70\% combustion efficiency [36], an average fire size throughout the whole fire is estimated to be approximately $30 \mathrm{MW}$. Calculated heat release rate (HRR) evolution based on the locations of leading and trailing edge of the fire is shown in Fig. 11. It indicates a growth of fire from $\sim 4 \mathrm{MW}$ at the beginning of fire to $\sim 70 \mathrm{MW}$ at the peak fire power (at approx. $12 \mathrm{~min}$ ).

The heat release rate (HRR) evolution shown in Fig. 11 is calculated in two steps.

Firstly, HRR per unit length is calculated. This is done by dividing the fuel load density (per unit length) by the local burning time $\left(t_{b}\right)$ at every position along the wood crib (Eq. 3). The local burning time is measured by the time difference between the arrival of the leading and trailing edges (Fig. 12, middle). The resulting profile is shown in Fig. 12 (left).

$$
\begin{aligned}
& \overline{\operatorname{HRR}^{\prime}}(x)=\frac{\rho_{f} W \Delta H_{c} \chi}{t_{b}(x)} \\
& H R R(t)=\int_{\text {trailing }(t)}^{\text {leading }(t)} \overline{H R R^{\prime}}(x) d x
\end{aligned}
$$

where $\rho_{f}$ is the fuel density $\left(19.38 \mathrm{~kg} / \mathrm{m}^{2}\right), W$ is the width of the crib $(6 \mathrm{~m}), \Delta H_{c}$ is the heat of combustion $(18.94 \mathrm{MJ} / \mathrm{kg})$, and $\chi$ is the combustion efficiency assumed to be $70 \%$ [36] for the base case.

Secondly, the HRR is then calculated by integrating the HRR per unit length between the leading and trailing edges at each time step (Eq. 4). This is shown in
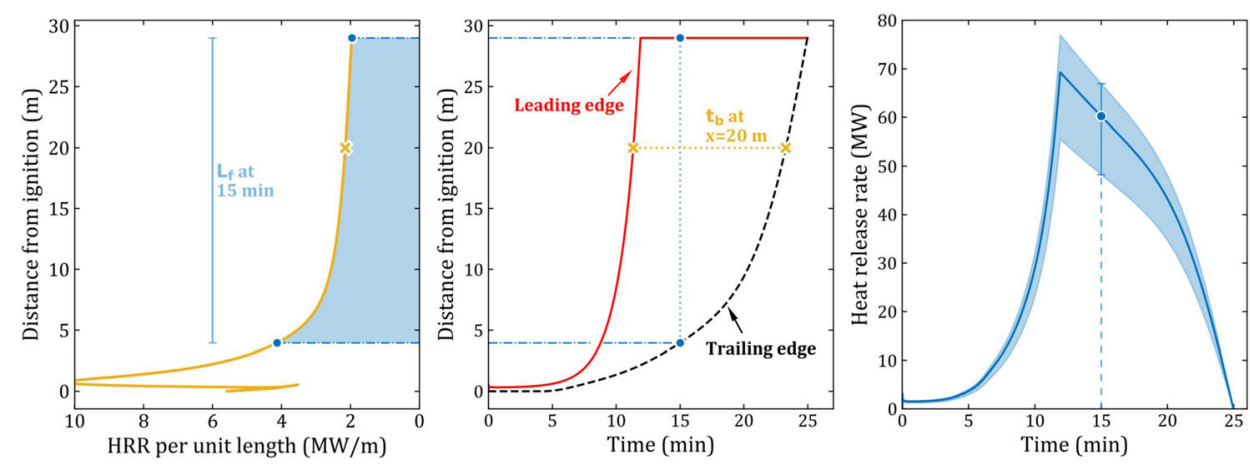

Figure 12. Illustration of the method used to calculate the heat release rate (HRR) evolution. HRR per unit length calculated using Eq. 3 (left); position of the leading and trailing edges with respect to time (middle); and resulting HRR evolution. $L_{f}$ for calculation of HHR at $15 \mathrm{~min}$ is used as an example in this figure. 
Fig. 12. The HRR per unit length is integrated over fire length along the crib, $L_{f}$, which is burning at a given time (shaded area shown in Fig. 12 which is defined by the position of the leading and trailing edges at a specific time of interest).

For example, at $15 \mathrm{~min}$, the leading edge has reached the far end of the crib (29 $\mathrm{m}$ from ignition) while the trailing edge is at $\sim 4 \mathrm{~m}$. The length of the crib between these edges (i.e. fire length, $L_{f}$ ) is burning, and thus the area under the HRR per unit length between these two points, as shown in Fig. 12, yields the HRR at this time.

The uncertainty associated with assumed combustion efficiency (0.6-0.75), wood density $\left(426-466 \mathrm{~kg} / \mathrm{m}^{3}\right)$, and heat of combustion $(18.94 \pm 0.14 \mathrm{MJ} / \mathrm{kg})$ is considered in the estimated HRR and is represented by a shaded area in Fig. 11. The area under the total HRR curve, which is the fuel burnt, the applied combustion efficiency, is $\sim 64,200 \mathrm{MJ}$ which deviates from the total fire load by $0.6 \%$ demonstrating a good conservation of energy and mass in the HRR calculations.

\subsection{Gas Phase Temperatures}

Gas phase temperature measurements at the beam soffit level at four locations along the fire path (at -2.8 m (T1), $4.6 \mathrm{~m}$ (T3), $15.9 \mathrm{~m}$ (T6), and $27.1 \mathrm{~m}$ (T9) from ignition towards the West entrance) are shown in Fig. 13. The shaded area repre-

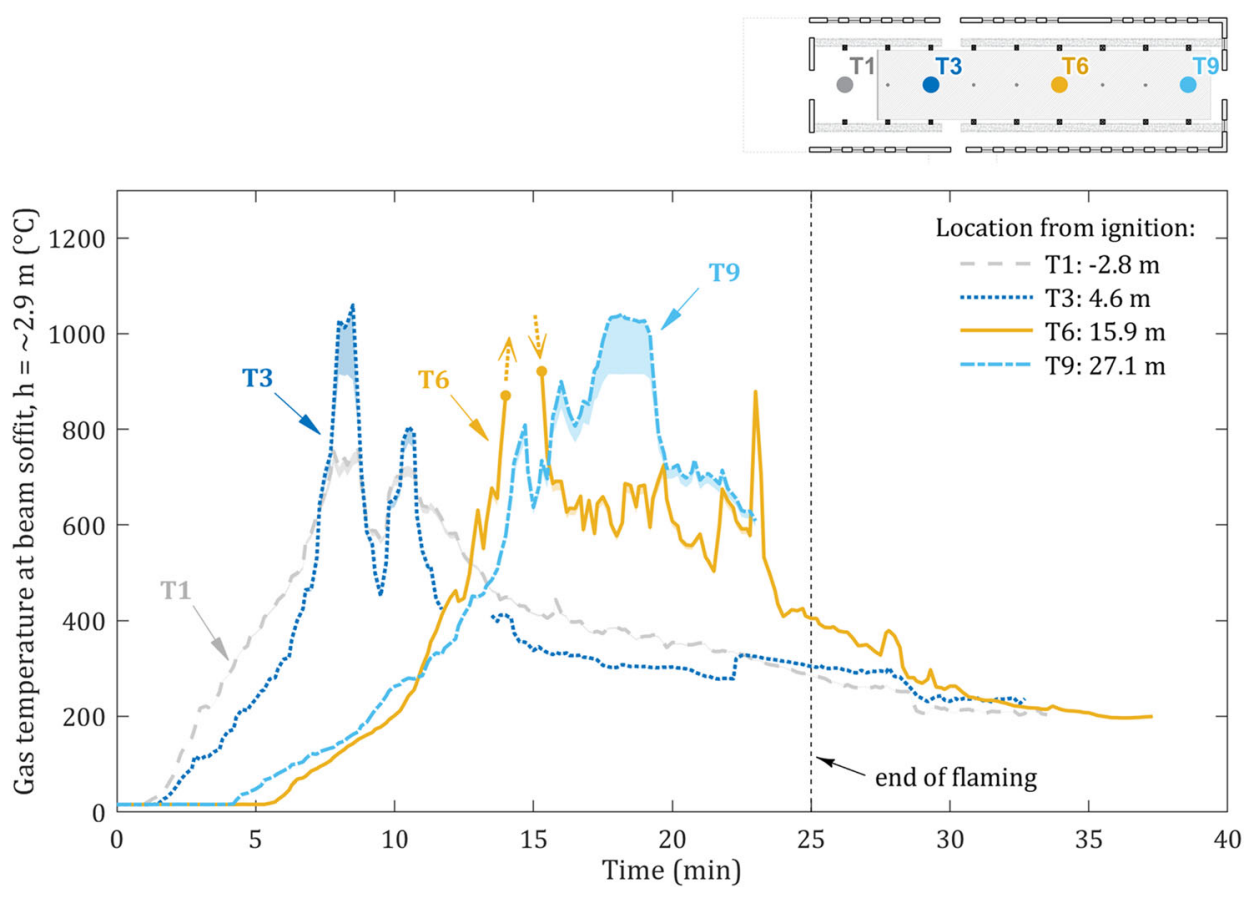

Figure 13. Gas phase temperature measurements at the beam soffit level at four locations along the fire path. No data is shown at the times when thermocouples T3 and T6 failed to record. Shaded area represents uncertainty in thermocouple data. 
sents thermocouple measurement uncertainty range (see Sect. 2.5). The near-field and far-field exposures can be clearly identified. Near-field represents flames impinging on the ceiling, while far-field represents smoke further away from the flames. Each thermocouple in the compartment, except for T1 which was not located above the fuel bed, was subjected to the near-field region. Once the nearfield had passed and flames had died out, the temperatures dropped to below $600^{\circ} \mathrm{C}$. The different times at which thermocouples were exposed to the near-field show that fire travelled across the compartment. Flames reached thermocouple T3 at $\sim 7 \mathrm{~min}$ and thermocouple T6 at $\sim 12 \mathrm{~min}$, thus, indicating an average spread of $\sim 31 \mathrm{~mm} / \mathrm{s}$.

In general, thermocouple measurements show highly non-uniform spatial temperature distributions in the compartment throughout the whole experiment dura-

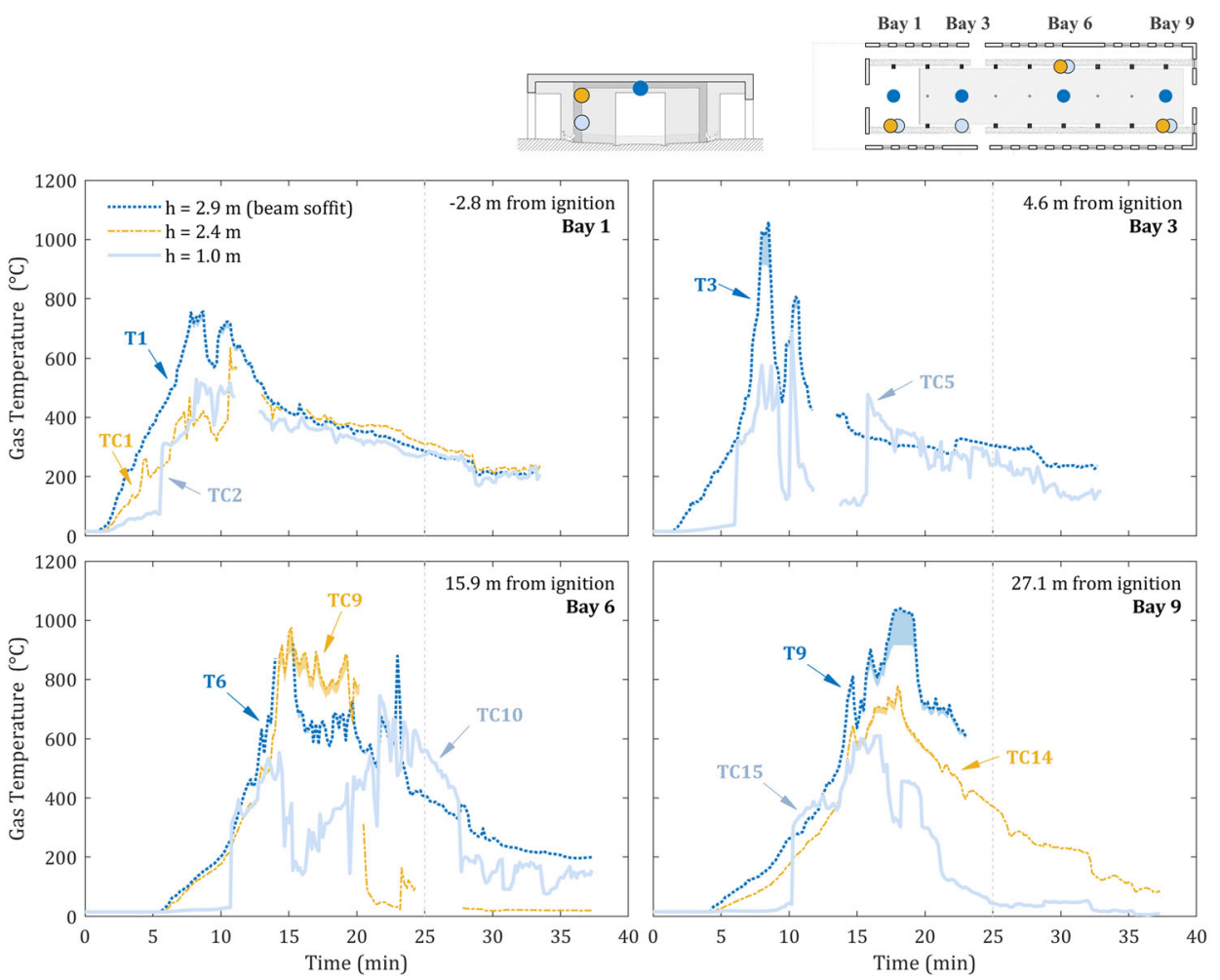

Figure 14. Vertical temperature variations within the compartment at the locations of four bays. Bay 1, Bay 3, Bay 6, and Bay 9 are representative of the same horizonfal thermocouple locations along the fire path as shown in Fig. 13. For each bay, $2.9 \mathrm{~m}, 2.4 \mathrm{~m}$, and 1 .O $\mathrm{m}$ indicate thermocouples located at the beam soffit, column top, and column bottom, respectively. Shaded area represents uncertainty in thermocouple data. 
tion. Horizontal temperatures across the ceiling level range from $120^{\circ} \mathrm{C}$ (T6) to $915-1030^{\circ} \mathrm{C}$ (T3) at $\sim 8 \mathrm{~min}$ and from $300^{\circ} \mathrm{C}$ (T3) to $915-1035^{\circ} \mathrm{C}$ (T9) at $\sim 18$ min. The latter corresponds to the horizontal spatial temperature differences of up to approximately $790-900^{\circ} \mathrm{C}$.

Vertical temperature variations are shown in Fig. 14, where thermocouple measurements close to columns at two different heights (i.e. $1 \mathrm{~m}$ and $2.4 \mathrm{~m}$ ) are compared to the measurements at the mid-span of the beam soffit $(\sim 2.9 \mathrm{~m}$ high $)$ in the same bay. One of the column thermocouples at Bay 3 failed, therefore, it is not shown. Figure 14 shows that at different times of the experiment vertical spatial temperature differences are in the range of approximately $50-700^{\circ} \mathrm{C}$. At Bay 1 , Bay 3, and Bay 9, higher temperatures are reported at the beam soffit level than at the columns. On the other hand, at Bay 6 , temperatures at the $\sim 2.4 \mathrm{~m}$ height are higher than at the ceiling at $\sim 2.9 \mathrm{~m}$ by up to approximately $350^{\circ} \mathrm{C}$. This is due to the deep layer of smoke which was reaching the top of the fuel bed towards the end of the compartment.

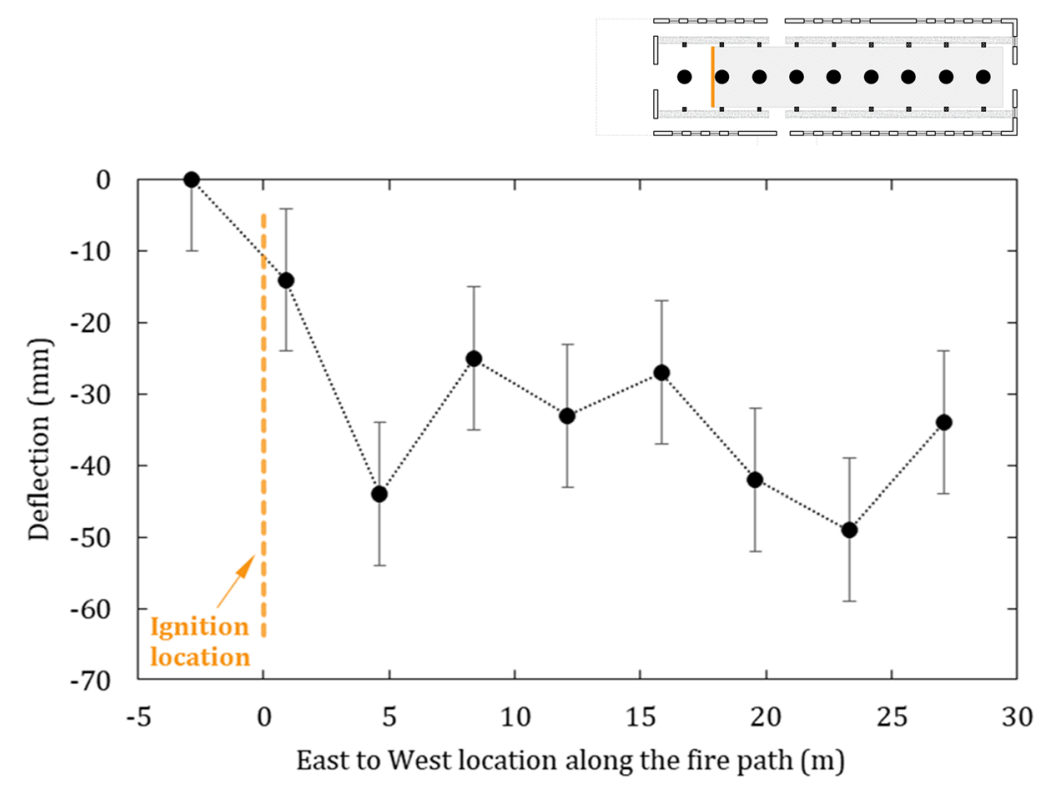

Figure 15. Mid-span deflections at beam-soffits after the experiment measured based on the 3D laser scans of the building before and after the experiment. Noted positions correspond to beam and column locations going from the East to the West side of the compartment. 


\subsection{Structural Deformations}

A 3D laser scan (see Sect. 2.5) of the compartment was conducted before and a few days after the experiment. The deflections at the mid-span of beam soffits were quantified by comparing the measurements before and after the fire and are illustrated in Fig. 15. The main sources of error associated with the measurement are falling of the mineral wool protection from beam soffits (Sect. 3.1), variability in the thickness of mortar patches used to apply mineral wool, and the process used to orient the scan data. The error is estimated to be approximately $\pm 10 \mathrm{~mm}$.

Deflections at beam soffits shown in Fig. 15 are relatively low and up to 50 $( \pm 10) \mathrm{mm}$. The maximum measured deflection is representative of the beam span ratio of span/100. Deflection failure criteria typically assumed in the fire engineering for serviceability limit state during the fire is span/10, which is 10 times higher than the measured deflections noted here. These deflections indicate that the building has likely sustained limited structural damage and that the fire was not a significant threat for this structure.

\section{Discussion}

Experimental observations and measurements indicate that the fire behaviour during $\mathrm{x}$-ONE is representative of a travelling fire which was fuel controlled. Clear leading and trailing edges have been observed as the fire spread across the fuel along the length of the compartment without reaching flashover.

As identified by Drysdale [34], criteria defining flashover are typically associated in literature with burning within the whole compartment volume, a heat flux at floor level of $20 \mathrm{~kW} / \mathrm{m}^{2}$, or an average upper layer temperature in the range of $450-670^{\circ} \mathrm{C}$. During $\mathrm{x}-\mathrm{ONE}$, flames spread across the fuel bed gradually and ignition of all fuel and burning within the whole volume of compartment was not observed. Heat flux levels on the floor, where the crib was, were in many places below the critical heat flux for ignition of $15 \mathrm{~kW} / \mathrm{m}^{2}$ ahead of the flame, because ignition was gradual. Gas temperatures ahead of the flames (i.e. the leading edge), both at the ceiling level and through the height of the compartment, were below $400^{\circ} \mathrm{C}$. In addition, external flaming, and smoke exhaust were only observed locally close to the fire locations. The latter characteristic and the gradual burning of fuel are indicative of a fire which is not ventilation controlled.

\subsection{Comparison to Design Fires}

4.1.1. Uniform Fires Traditional design curves for compartment fires, which are commonly used in structural fire design, such as the standard fire and Eurocode parametric fire curves, have been developed on the assumption of uniform burning and uniform temperatures in the compartment. As per Eurocode 1 [2], parametric temperature-time curves can be used for compartments with floor areas up to $500 \mathrm{~m}^{2}$ and floor to ceiling heights up to $4 \mathrm{~m}$. However, during the experiment reported in this paper which was conducted in a compartment with a floor area of 


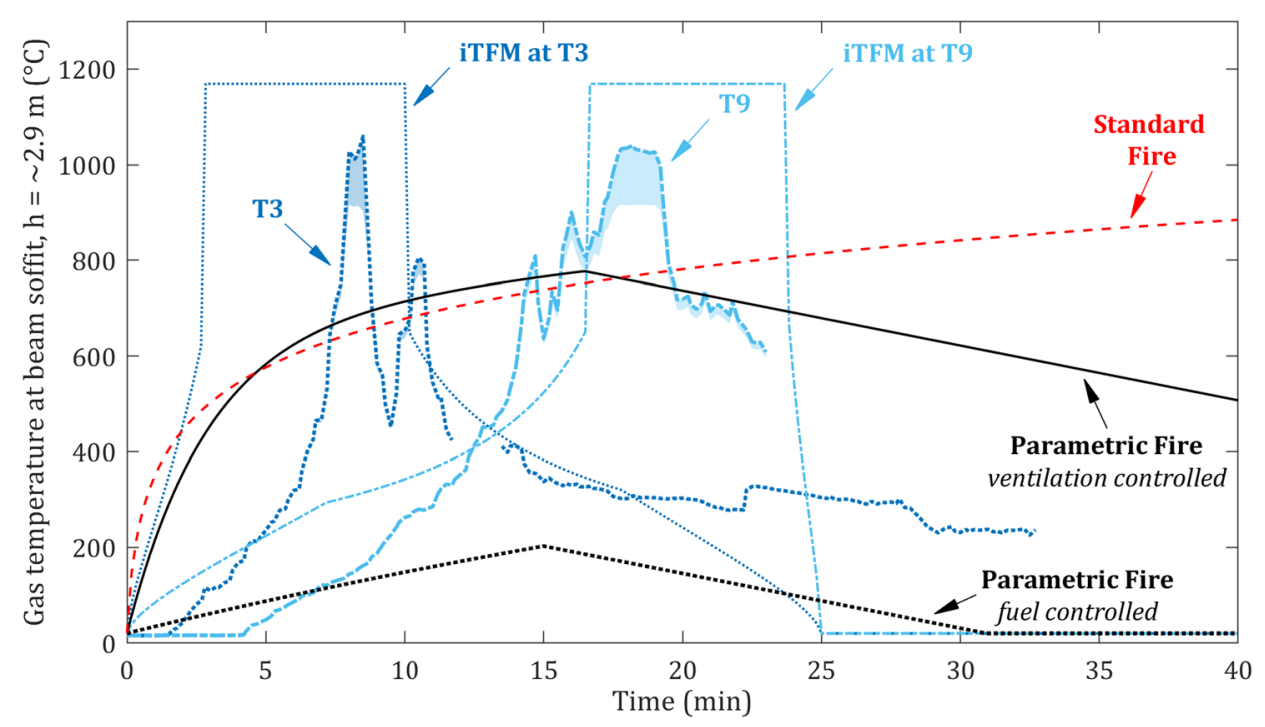

Figure 16. Comparison between the gas phase temperature measurements recorded during the experiment and standard and Eurocode parametric fire curves, and representative travelling fire gas temperafure curves generafed using iTfM [ 31 ].

$380 \mathrm{~m}^{2}$, we can already observe highly non-uniform burning and gas temperature distributions.

Comparison between the gas phase temperature measurements recorded during the experiment and standard and Eurocode parametric fire curves for the experimental compartment is shown in Fig. 16. Fuel and ventilation controlled parametric curves represent fires with a fuel load of $168 \mathrm{MJ} / \mathrm{m}^{2}$ (equivalent to the total fuel load from the crib) and $370 \mathrm{MJ} / \mathrm{m}^{2}$, respectively, distributed over the whole compartment floor area $\left(380 \mathrm{~m}^{2}\right)$ and $70 \%$ combustion efficiency [36]. Figure 16 indicates significant differences in the thermal exposure such as fire duration, peak temperatures, heating and cooling that would be considered in the design of structure with a similar compartment.

4.1.2. Travelling Fires Over the past two decades a number of methodologies and design approaches have been developed to represent travelling fires [12, 13, 17, 31, 37-39]. The first approaches for consideration of non-uniform fires were developed in 1996 by Clifton [38] and Bailey et al. [13]. However, travelling fires were not considered in the design until a decade ago, 2006, after Stern-Gottfried and Rein $[11,12]$ introduced the term travelling fires. Other methodologies have been developed since [12, 13, 17, 31, 37-39].

All of the travelling fire methodologies to date assume a constant fire spread rate and burning rate. During the $\mathrm{x}$-ONE experiment, fire spread rate was observed not to be constant but to gradually accelerate. In addition, the flame 
front and trailing edge spread velocities were both different and, as a result, the fire was growing in size. A predefined fire size is a common input needed in travelling fire methodologies. The accelerating nature of fire is likely related to compartment characteristics (i.e. compartment area, available ventilation, etc.), and fuel load and its' arrangement. However, it is difficult to estimate the impact on the basis of one experiment. Further experimental research is needed to determine the key factors influencing the development of travelling fires in large enclosures.

Comparison of representative travelling fire gas temperature curves generated using iTFM [31] with gas phase temperatures measured during the experiment at two different locations is illustrated in Fig. 16. The travelling fire assumes the same fuel load area and density as used for the experiment $(6 \mathrm{~m} \times 29 \mathrm{~m}, 370 \mathrm{MJ} /$ $\mathrm{m}^{2}$ ), $70 \%$ combustion efficiency [36], an average fire size of $40.32 \%$ (based on the positions of leading and trailing edges), and a HRR of $601 \mathrm{~kW} / \mathrm{m}^{2}$, which was selected to get a similar fire duration to that in the experiment $(25 \mathrm{~min})$. Figure 16 shows that iTFM significantly overpredicts near-field heating duration close to the ignition location (i.e. T3). This is because the methodology assumes a uniform flame spread and cannot capture the changing fire size. The fire size selected on the basis of the total fire exposure is more representative of the fire size towards the end of the experiment (i.e. T9). In general, the temperatures assumed in iTFM are closer to the observed experimental results and more conservative than uniform traditional design fires and are able to account for highly non-uniform temperature distributions within the compartment.

\section{Conclusions}

With a floor area of $380 \mathrm{~m}^{2}, x-O N E$ is the largest compartment fire experiment in terms of open-plan floor area carried out to date. A travelling fire with clear leading and trailing edges was observed.

The fire travelled quickly across the compartment and burned out at the far end $25 \mathrm{~min}$ after ignition. Flashover was not observed. At all thermocouple locations along the fire path clear near-field and far-field regions could be observed indicating highly non-uniform temperature distributions within the compartment.

Flame spread rate and burning rate over a continuous wood crib fuel were observed not to be constant but accelerating and, thus, resulting in a gradually increasing fire size. The estimated average fire size is $30 \mathrm{MW}$ with $\sim 70 \mathrm{MW}$ at the peak fire power. This accelerating nature is not currently considered in any of the travelling fire methodologies proposed in the literature.

Fire dynamics observed during the $x-O N E$ experiment show that real compartments with large enclosures have completely different fire dynamics to fires reported in smaller experiments which are used as a basis for uniform design fire curves presented in the standards. This highlights the need for further experimental work to improve our understanding of travelling fire dynamics under a range of different conditions (i.e. compartment size, ventilation, fuel load, etc.), and to develop and improve design methodologies which would be able to quantify travelling fire dynamics and which could be incorporated in the design of modern structures. 
$x-O N E$ is the first of a series of experiments within the same compartment. The results of this experiment could be used in the future to improve design methodologies and further experiments.

\section{Acknowledgements}

This research has been funded by Centre d'Études et de Recherches de l'Industrie du Béton (CERIB, France), Ove Arup and Partners Limited (UK), the Engineering and Physical Sciences Research Council (EPSRC, UK), and Educational and Scientific Foundation of the Society of Fire Protection Engineers (SFPE, USA) in collaboration with Imperial College London (UK), Instytut Techniki Budowlanej (ITB, Poland), and The Main School of Fire Service (Poland). Authors would like to thank Harry Mitchell for the help in preparation of this manuscript. Data supporting this paper can be obtained from https://zenodo.org/collection/user-imperia lhazelab under a Creative Commons Attribution license.

\section{Open Access}

This article is licensed under a Creative Commons Attribution 4.0 International License, which permits use, sharing, adaptation, distribution and reproduction in any medium or format, as long as you give appropriate credit to the original author(s) and the source, provide a link to the Creative Commons licence, and indicate if changes were made. The images or other third party material in this article are included in the article's Creative Commons licence, unless indicated otherwise in a credit line to the material. If material is not included in the article's Creative Commons licence and your intended use is not permitted by statutory regulation or exceeds the permitted use, you will need to obtain permission directly from the copyright holder. To view a copy of this licence, visit http://creat ivecommons.org/licenses/by/4.0/.

\section{Appendix 1 : Flame Defection}

During the $\mathrm{x}-\mathrm{ONE}$ experiment, in addition to the thermocouple measurements, a series of optical cameras (GoPro, handheld and mobile cameras) were used to capture the fire size and flame spread rates. Adapting the tomographic reconstruction approach by Graham [40], the footage from the cameras was used for image processing analysis [40] in MATLAB. The procedure for this analysis is described below. 

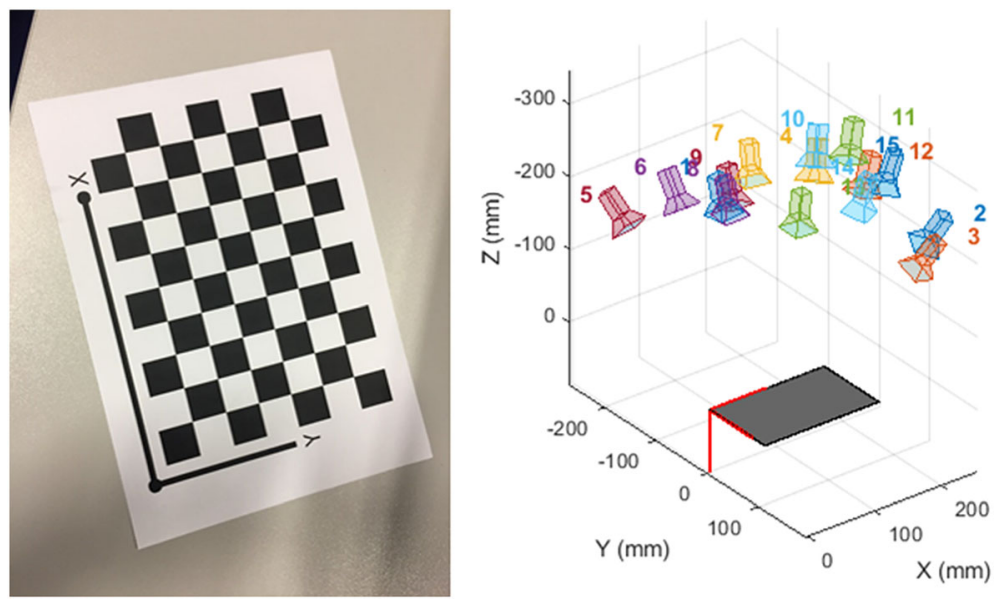

\section{Figure 17. Checkerboard pattern used for camera calibration (left); and detected camera locations in respect to the checkerboard pattern using camera calibration from a series of images taken at different angles (right).}

\section{Camera Calibration}

Each camera was calibrated using the Camera Calibration toolbox implemented by MATLAB [41] in order to obtain camera parameters such as intrinsic matrix, focal length, and distortion. A series of images of a printed checkerboard pattern with $21.5-23 \mathrm{~mm}$ grid were taken from different angles and processed (see Fig. 17). Determined camera parameters were then used to correct for image distortion in each photo used for flame detection and detection of camera location at the time the image was taken.

\section{Camera Location Detection}

During the experiment most of the cameras were not located at fixed known positions in respect to the building. Furthermore, some of the photos have been taken using handheld and mobile cameras. Therefore, detection of camera location at the time each image was taken was carried out by selecting a minimum of fifteen points (for increased accuracy) in the undistorted image with known coordinates within the building. Building dimensions and coordinates were obtained from the three-dimensional laser scan carried out before the experiment (presented in Sect. 2.1).

The MATLAB function estimateWorldCameraPose, which uses the perspectivethree-point algorithm [42], was then used to estimate camera location in respect to the building from 3-D (e.g. known coordinates of selected points in the global building coordinate system) to 2-D point (e.g. selected point/pixel coordinates within local camera coordinate system) correspondences. Figure 18 illustrates selected points on an undistorted image, and 3D building coordinate system with the detected camera location for a representative photo. 

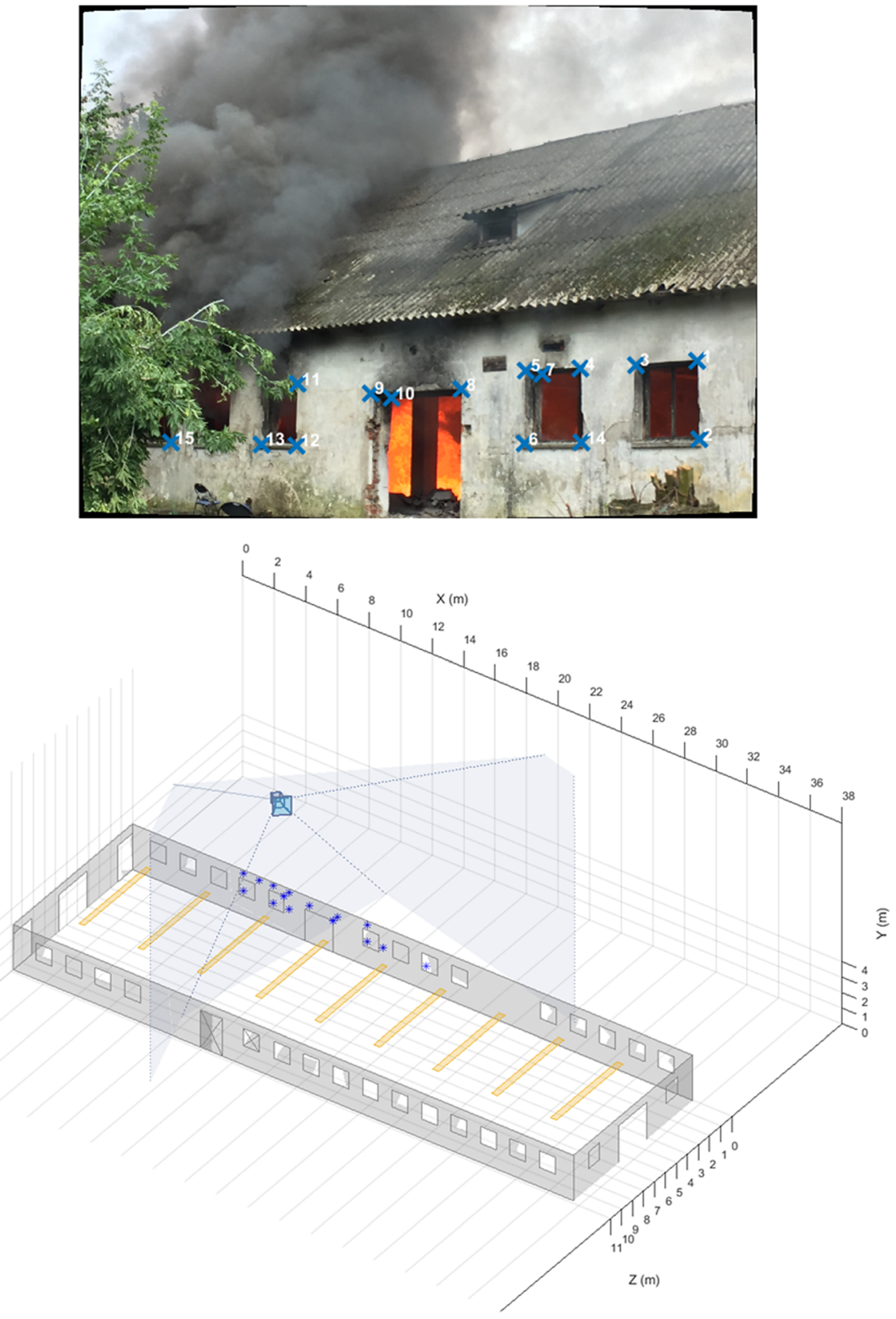
4Figure 18. Undistorted representative photo taken at the South entrance of the building with blue crosses $(x)$ indicating selected points with known building coordinates for detection of camera location (fop); and 3D building coordinate system with the detected camera location for the photo above (bottom). In the bottom image, blue stars ( ${ }^{*}$ ) indicate locations of selected points. The 3D image indicates internal wall surfaces, thus, some of the selected points appear offset.

\section{Flame Detection in Images}

Flame detection in each photo has been carried out by assessing pixel colour characteristics and combining flame detection thresholds proposed by Chen and Bao [43] and Qureshi et al. [44]. Thresholds used to filter flame pixels are as follows:

\begin{tabular}{lll}
\hline Threshold 1: & $R \geq G \geq B$ & (as per Chen and Bao [43]) \\
Threshold 2: & $Y_{1} \geq S \geq Y_{2}$ & (as per Chen and Bao [43]) \\
Threshold 3: & $R>R_{(}$ & (as per Qureshi et al. [44]) \\
Threshold 4: & $S \geq\left((255-R) \times \frac{S_{T}}{R_{T}}\right)$ & (as per Qureshi et al. [44]) \\
Threshold 5: & $V>V_{T}$ & (as per Qureshi et al. [44]) \\
\hline
\end{tabular}

where $R, G$, and $B$ represent Red, Green, and Blue colour components for a given pixel in the RGB colour space. $S$ and $V$ represent Saturation and Value for a

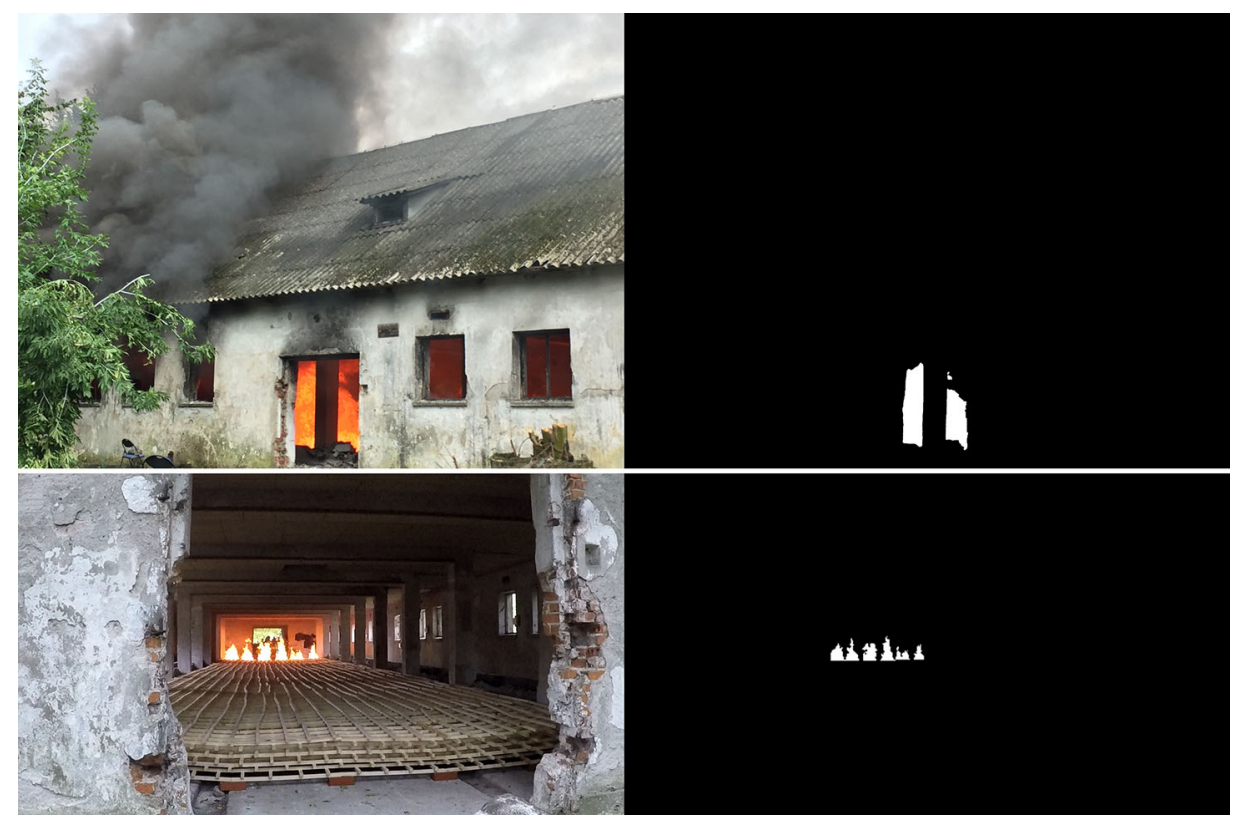

Figure 19. Representative mobile (top) and GoPro (bottom) images showing detected location of the flame pixels (right). 
given pixel in the HSV colour space. $Y_{1}$ and $Y_{2}$ denote threshold functions for the relation between Saturation and Blue colour components as described by Chen and Bao [43]. For each individual camera, separate $Y_{1}$ and $Y_{2}$ threshold functions are determined using training flame pixels selected from the photos taken with a given camera. Similarly, $R_{T}, S_{T}$, and $V_{T}$ represent empirical thresholds for different colour components as described by Qureshi et al. [44] that are determined using training flame pixels for each camera. The same thresholds cannot be applied to all images because of different individual camera parameters and settings used (e.g. aperture, shutter speed, light sensitivity, etc.) when images were taken. Different camera settings would affect the colour component values of flames captured in images (e.g. brightness of the flames). Figure 19 illustrates detected flame pixels for representative photos.

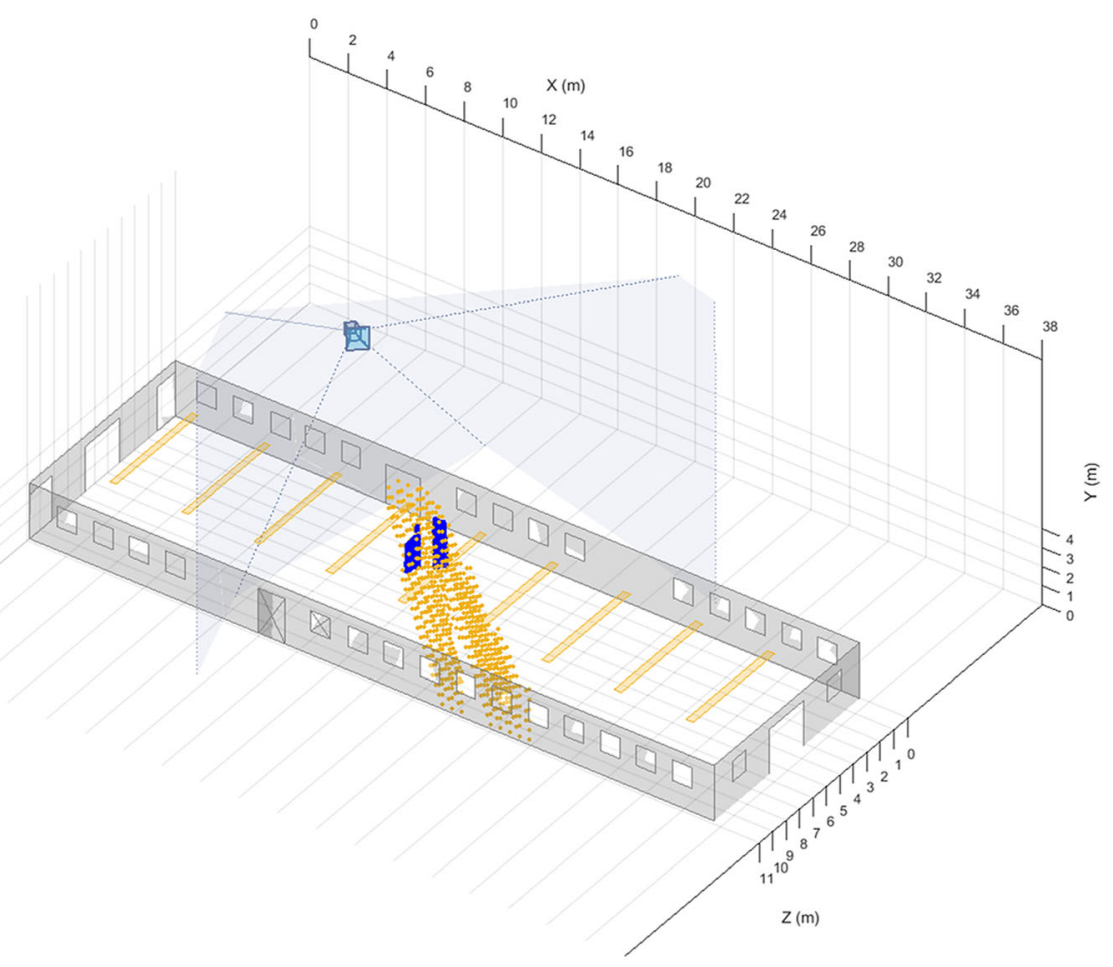

Figure 20. Voxels defected as flame pixel ray reprojections (yellow). Blue areas represent reprojection of all detected flame pixels at a prescribed distance from the camera. 


\section{Flame Location in the Building}

The building has been subdivided into multiple voxels which represent three-dimensional cube-shaped elements centred on a node [40]. Based on convergence studies and for computational efficiency, each voxel had approximate dimensions of $0.5 \mathrm{~m} \times 0.5 \mathrm{~m} \times 0.5 \mathrm{~m}$.

Knowing camera coordinates and orientation in the global building coordinate system, for simplicity and computational efficiency (as in [40]) every pixel detected to represent flames was approximated to a single ray in the building coordinate system. An algorithm was developed to determine the geometric relationship between building voxels and projected flame pixel rays. A flame pixel ray is considered to pass through the voxel (i.e. a possible flame location in the building) if the perpendicular distance between the pixel ray and voxel node is less than the pitch between the voxel nodes (as in [40]). Figure 20 illustrates voxels detected as flame pixel ray reprojections. These voxels indicate possible flame locations in the building.

For each given image taken during the experiment voxels determined to indicate possible flame locations were further processed by comparing against detected possible flame voxels from a different camera angle taken at the same time. If views from two cameras indicated the same voxel as a possible flame location, the voxel was considered as confirmed flame location. Similarly, some voxels were discounted as possible flame locations if views from a different camera, not obstructed by building structure, clearly indicated that no flames were present at specific voxel coordinates.

Due to the lack of simultaneous camera views from different angles a complete 3D flame reconstruction could not be carried out for this experiment. The GoPro camera took continuous footage from the West entrance of the building and, thus, was mainly used to detect the flame front location (i.e. leading edge) at different times. Most of the footage from the handheld and mobile cameras was taken from the South side of the building and, therefore, was mainly used to estimate the location of the trailing edge. The error associated with image processing and flame detection is estimated to be approximately $\pm 0.25 \mathrm{~m}$ and $\pm 0.5 \mathrm{~m}$ for the leading and trailing edges, respectively. Error associated with the trailing edge detection is higher due to the use of data from handheld and mobile cameras.

\section{Appendix 2: Human Dimensions}

$\mathrm{x}$-ONE experiment could not have been possible without the extraordinary teamwork of an international group of collaborators. In this appendix, we want to highlight the human factors involved in any research that is developed. As a community, we tend to forget the work that is behind any experiment, and any new 


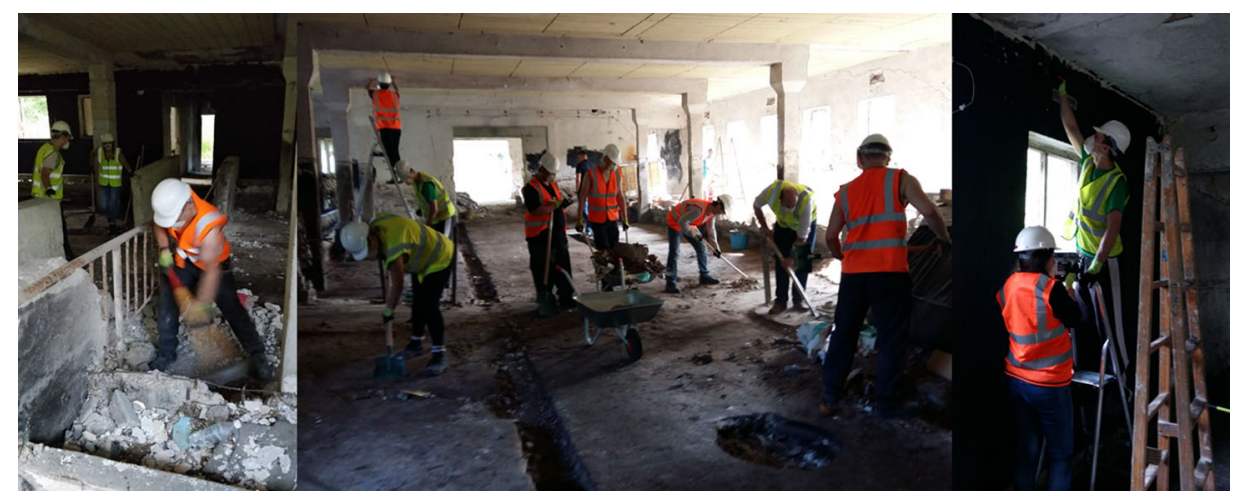

Figure 21. Illustration of the demanding physical labour that went into preparing the site before the experiment.

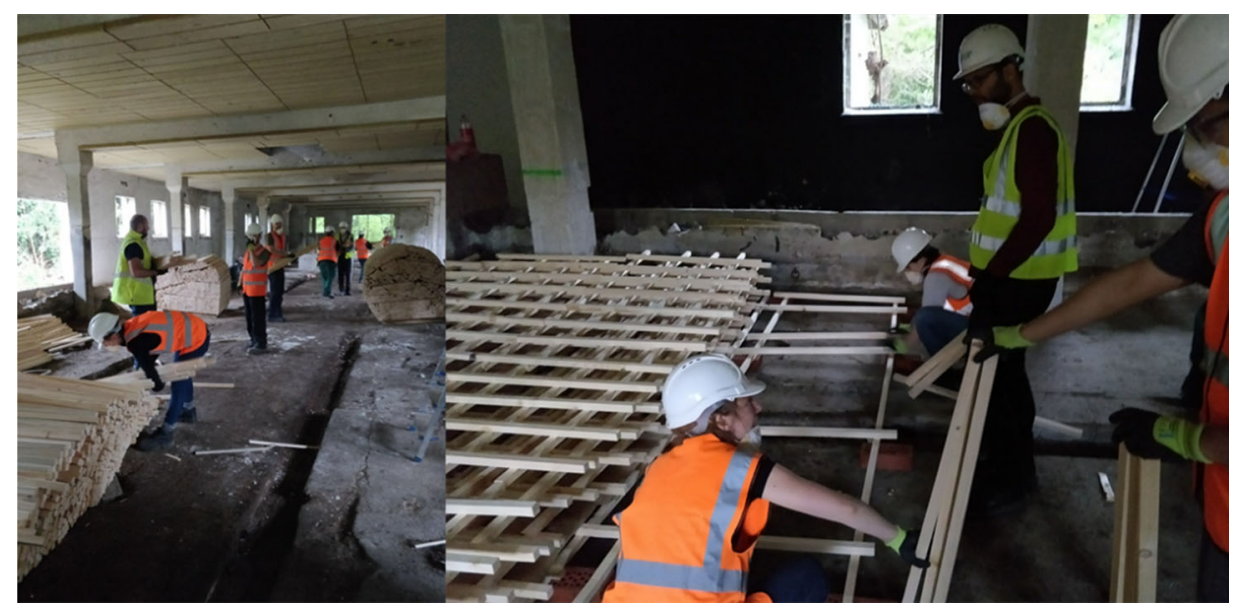

Figure 22. Illustration of the process of building the vast crib used to fuel the fire. 


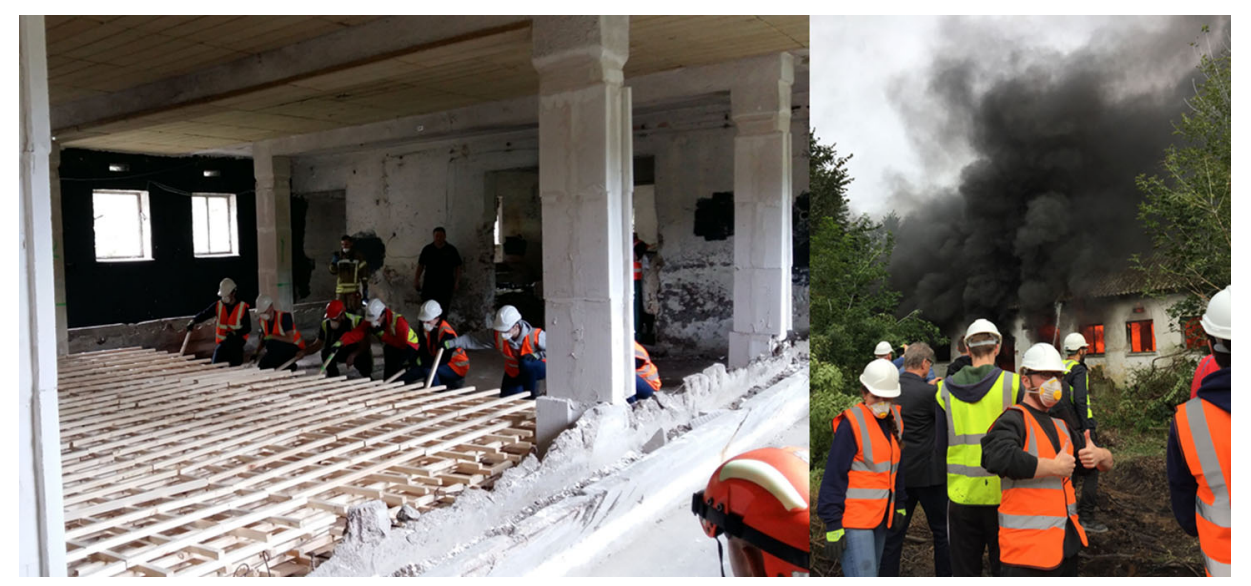

\section{Figure 23. Ignition of the experiment (left), and the happy scientists observing the fruits of their labour (right).}

result. How many of us reflect over the hours of work and effort that is behind each one of the dots that we see in a graph? It is important to emphasize this, and to always remember the group of people that make all of this possible.

The fire itself lasted minutes, but to achieve this goal, we went through a myriad of tasks starting with finding the ideal building and designing the fuel load to finding suppliers and arranging what may be simple things such as accommodation for all of us.

The building where the test took place is an abandoned farm located in the countryside nearby Warsaw. What is shown in the manuscript pictures is the final state of the building when we run the experiment, but what is not shown is the hard work and determination needed to get it ready for the experiment after decades of decay (Figs. 21, 22, 23).

\section{References}

1. ISO (1999) ISO 834-1 Fire-resistance tests - elements of building construction. Part 1: General requirements

2. CEN (2002) EN 1991-1-2:2002-Eurocode 1. Actions on structures. General actions. Actions on structures exposed to fire. Brussels

3. Franssen J-M (2000) Improvement of the parametric fire of Eurocode 1 based on experimental test results. Fire Saf Sci 6:927-938

4. Jonsdottir AM, Rein G (2009) "Out of range". Fire Risk Management, pp 14-17

5. Bohm B, Hadvig S (1982) Nonconventional fully developed polyethylene and wood compartment fires. Combust Flame 44:201-221

6. Lennon T, Moore D (2003) The natural fire safety concept-full-scale tests at Cardington. Fire Saf J 38(7):623-643

7. Rein G, Empis CA, Carvel R (2007) The Dalmarnock fire tests: experiments and modelling. University of Edinburgh, Edinburgh 
8. Stern-Gottfried J, Rein G, Bisby L, Torero JL (2010) Experimental review of the homogeneous temperature assumption in post-flashover compartment fires. Fire Saf $\mathbf{J}$ 45(4):249-261

9. Stern-Gottfried J, Rein G (2012) Travelling fires for structural design - part I: literature review. Fire Saf J 54:74-85

10. Lamont S, Usmani AS, Gillie M (2004) Behaviour of a small composite steel frame structure in a 'long-cool' and a 'short-hot' fire. Fire Saf J 39(5):327-357

11. Law A, Stern-Gottfried J, Gillie M, Rein G (2011) The influence of travelling fires on a concrete frame. Eng Struct 33(5):1635-1642

12. Stern-Gottfried J, Rein G (2012) Travelling fires for structural design-part II: design methodology. Fire Saf J 54:96-112

13. Bailey CG, Burgess IW, Plank RJ (1996) Analyses of the effects of cooling and fire spread on steel-framed buildings. Fire Saf J 26(4):273-293

14. Rackauskaite E, Kotsovinos P, Jeffers A, Rein G (2017) Structural analysis of multi-storey steel frames exposed to travelling fires and traditional design fires. Eng Struct 150:271-287

15. Röben C (2009) The effect of cooling and non-uniform fires on structural behaviour. $\mathrm{PhD}$ thesis. The University of Edinburgh

16. Kotsovinos P (2013) Analysis of the structural response of tall buildings under multifloor and travelling fires. PhD thesis. The University of Edinburgh

17. Dai X, Welch S, Usmani A (2017) A critical review of 'travelling fire' scenarios for performance-based structural engineering. Fire Saf J 91:568-578

18. Kirby BR, Wainman DE, Tomlinson LN, Kay TR, Peackok BN (1994) Natural fires in large scale compartments - a British steel technical. Fire Research Station collaborative project." British Steel Technical

19. Horová K, Jána T, Wald F (2013) Temperature heterogeneity during travelling fire on experimental building. Adv Eng Softw 62-63:119-130

20. Wald F, Jána T, Horová K (2011) Design of joints to composite columns for improved fire robustness: to demonstration fire tests. Czech Technical University, No. September, p 25

21. Torero JL, Majdalani AH, Abecassis-empis C, Cowlard A (2014) Revisiting the compartment fire. In: Proceedings of the 11th international symposium on fire safety science

22. Hidalgo JP, Cowlard A, Maluk C, Kahrmann S, Hilditch R, Krajcovic M, Torero JL, Majdalani AH (2017) An experimental study of full-scale open floor plan enclosure fires. Fire Saf J 89:22-40

23. Hidalgo JP, Goode T, Gupta V, Cowlard A, Abecassis C, Maclean J, Bartlett AI, Maluk C, Montalvá JM, Osorio F, Torero JL (2019) The Malveira fire test: full-scale demonstration of fire modes in open-plan compartments. Fire Saf J 108:102827

24. Rush D, Dai X, Lange D (2021) Tisova Fire Test - Fire behaviours and lessons learnt. Fire Saf J 121:103261

25. Thomas PH, Heselden AJM, Law M (1967) Fully-developed compartment fires - two kinds of behaviour. Fire research technical paper no. 18. HMSO, London

26. British Steel (1999) The behaviour of multi-storey steel framed buildings in fire. Rotherham

27. Rackauskaite E, Rein G (2020) Wood cribs and fuel load design for large-scale travelling fire experiments. London, UK. https://doi.org/10.5281/zenodo.5361036

28. Thomas PH (1986) Design guide: structure fire safety CIB W14 workshop report. Fire Saf J 10(2):77-137 
29. BSI (2003) PD 7974-1:2003 application of fire safety engineering principles to the design of buildings - part 1: initiation and development of fire within the enclosure of origin

30. Quintiere JG, McCaffrey BJ (1980) Burning of wood and plastic cribs in an enclosure. Final report, vol 1 and 2

31. Rackauskaite E, Hamel C, Law A, Rein G (2015) Improved formulation of travelling fires and application to concrete and steel structures. Structures 3:250-260

32. SpecialMetals (2008) INCONEL alloy 600. Publication number SMC-027

33. Welch S, Jowsey A, Deeny S, Morgan R, Torero JL (2007) BRE large compartment fire tests - characterising post-flashover fires for model validation. Fire Saf J 42(8):548567

34. Drysdale D (2011) An introduction to fire dynamics, 3rd edn. Wiley, London

35. Heidari M (2021) Travelling fires methodology and probabilistic design of structures. $\mathrm{PhD}$ thesis. Imperial College London

36. Quintiere JG (1998) Principles of fire behaviour. Cengage learning. CRC Press, Boca Raton

37. Heidari M, Kotsovinos P, Rein G (2019) Flame extension and the near field under the ceiling for travelling fires inside very large compartments. Fire Mater 44:423-436

38. Clifton CG (1996) Fire models for large firecells. HERA report R4-83

39. Hopkin DJ (2013) Testing the single zone structural fire design hypothesis. In: Interflam 2013, proceedings of the 13th international conference, pp 139-150

40. Graham D (2016) Tomographic reconstruction of a swirling flame. MEng thesis. Imperial College London

41. Bouguet J-Y (2015) Camera calibration toolbox for Matlab. http://www.vision.calte ch.edu/bouguetj/calib_doc/. Accessed 19 July 2020

42. Gao X-S, Hou X-R, Tang J, Cheng H-F (2003) Complete solution classification for the perspective-three-point problem. IEEE Trans Pattern Anal Mach Intell 25(8):930-943

43. Chen J, Bao Q (2012) Digital image processing based fire flame color and oscillation frequency analysis. Procedia Eng 45:595-601

44. Qureshi WS, Ekpanyapong M, Dailey MN, Rinsurongkawong S, Malenichev A, Krasotkina O (2016) QuickBlaze: early fire detection using a combined video processing approach. Fire Technol 52(5):1293-1317

Publisher's Note Springer Nature remains neutral with regard to jurisdictional claims in published maps and institutional affiliations. 